\title{
"Books I Used as a Child were Mathematically Incorrect": Reasons to Use Children's Shape-Related Books as a Resource to Improve Mathematical Knowledge for Teaching
}

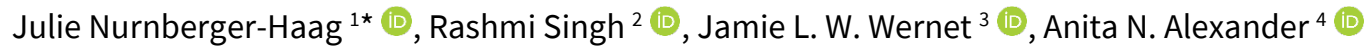

\author{
${ }^{1}$ Kent State University, Kent, OH, USA \\ ${ }^{2}$ Boston University, Boston, MA, USA \\ ${ }^{3}$ Lansing Christian School, Lansing, MI, USA \\ ${ }^{4}$ University of Bilkent, Ankara, TURKEY \\ *Corresponding Author: jnurnber@kent.edu
}

Citation: Nurnberger-Haag, J., Singh, R., Wernet, J. L., \& Alexander, A. N. (2021). “Books I Used as a Child were Mathematically Incorrect”: Reasons to Use Children's Shape-Related Books as a Resource to Improve Mathematical Knowledge for Teaching. International Electronic Journal of Mathematics Education, 16(3), em0642. https://doi.org/10.29333/iejme/10941

\section{ARTICLE INFO}

Received: 28 May 2020

Accepted: 5 Apr. 2021

\begin{abstract}
Some goals of mathematics teacher education include ensuring that pre-service teachers (PSTs) have strong content knowledge, the skill to anticipate and interpret student thinking, the ability to plan how to respond, and the ability to critically select resources for instruction. These goals are especially challenging for the topic of geometric shapes. Thus, we share an instructional activity that focuses PSTs' attention on an inaccurate resource of geometric information, children's books, to accomplish these goals in mathematics content as well as methods courses. Analyses of surveys and content assessments conducted to assess efficacy of the Shape Book Critique Activity were interpreted with the Mathematical Knowledge for Teaching (MKT) framework. Based on the findings we suggest that this short 40-minute activity is a promising way to promote PSTs' growth in three aspects of MKT for geometric shapes.
\end{abstract}

Keywords: geometry, pre-service teacher, mathematical knowledge for teaching, teacher education

\section{INTRODUCTION AND THEORETICAL FRAMEWORK}

Mathematics teacher educators have the unique challenge of ensuring that pre-service teachers (PSTs) have strong content knowledge as well as the skills to anticipate, interpret, and respond to student thinking. Overcoming this challenge is especially difficult within the limited time constraints that mathematics teacher educators have to develop (or transform) PSTs' knowledge and skills. Accurately classifying geometric shapes, a task average adults consider "simple," has been found to be difficult for adults throughout the world including in-service teachers and PSTs (Luneta, 2014; Sunzuma \& Maharaj, 2019; Tsamir et al., 2015). This difficulty became a problem of practice for the first author while working as a secondary teacher and mathematics coordinator at a school for grades 1-12. In this capacity, the first author was approached by an elementary teacher who was frustrated that her colleagues were teaching students that a square was mutually exclusive from a rectangle. The first argument her colleagues made was about the validity of definitions. Once the teacher convinced her colleagues to accept that a hierarchical definition of a rectangle was mathematically valid (e.g., de Villiers, 1994), they argued that this idea was inappropriate for the elementary students they served; rather, they believed children had to learn a partitive definition. This exchange served as a catalyst to conduct a line of research focused on early sources of peoples' mathematics concepts, and in this manuscript we use the anecdote of this exchange to aid the reader to think about the theoretical framework of Mathematical Knowledge for Teaching in a way that is relevant to the current study.

Elementary students need teachers who have accurate content knowledge of geometric shapes, understand how informal environmental sources influence their students' concepts before formal school instruction, and understand that even their youngest students are capable of more complex thinking than visual-level prototype matching. In this report, we use the Mathematical Knowledge for Teaching framework (Hill et al., 2008) to address this problem of practice by examining PSTs' responses to an activity designed to provoke PSTs to confront their own understandings. The Mathematical Knowledge for Teaching framework consists of the following components: Common Content Knowledge, Specialized Content Knowledge, Knowledge of Content and Students, Knowledge of Curriculum, and Knowledge of Curriculum and Teaching (Hill et al., 2008). Specialized Content Knowledge (i.e., knowing many correct ways and definitions of the same mathematical ideas or knowing how to select images that would uncover particular known issues with student reasoning) and Knowledge of Curriculum (i.e., knowing 
the standards and how specific content builds across time) are crucial components of knowledge that PSTs need to develop (Ball et al., 2008; Hill et al., 2008). Although important, these components were beyond the scope of the goals of the single instructional activity reported in this study. Thus, we focus on the three components of Mathematical Knowledge for Teaching that were designed into the instructional activity presented here: Common Content Knowledge, Knowledge of Content and Students, and Knowledge of Content and Teaching.

\section{Common Content Knowledge}

In the anecdote with which we began this manuscript, the in-service teachers' first argument that a square is not a rectangle reflected issues with their Common Content Knowledge of geometric shapes - that is, the knowledge of shapes any adult competent in mathematics would have (Ball et al., 2008). Having some accurate way to solve problems involving mathematics is considered Common Content Knowledge (Ball et al., 2008). In other words, in careers other than teaching or in life a person need not have a repertoire of particular ways to solve mathematical problems as long as they can solve mathematical problems accurately with understanding (Ball et al., 2008). The term "common" in Common Content Knowledge is meant to refer to knowledge that is commonly taught as a basis for varied future careers or "used in settings other than teaching," not knowledge that all adults would commonly have (Ball et al., 2008, p. 399). For example, accurately solving for an unknown length of a side or angle of a polygon would be considered Common Content Knowledge. In terms of classifications of shapes, knowing hierarchical definitions that a square is a subset of the class of rectangles, rhombi, and parallelograms helps a person concisely interpret properties of the shapes to solve problems (de Villiers, 1994), which can be used in a myriad of careers that use mathematics. Thus, this is knowledge that is not unique to teaching.

\section{Knowledge Specific to Teaching}

In the anecdote, the in-service teachers remained committed to the claim that elementary students should not be taught that a square is a rectangle. They tried two different arguments to support this claim, the first about the mathematics itself and then how students should learn mathematics. Specifically, once teachers accepted the Common Content Knowledge that a hierarchical definition of a rectangle was mathematically valid, the in-service teachers' second argument revealed their misguided understandings related to knowledge unique to teaching. Specifically, the in-service teachers lacked understanding of students' knowledge and capabilities related to shapes and what representations of shapes would best support learning, and expressed outdated understandings of early childhood mathematics. These misunderstandings reflect two subtypes of knowledge that Ball and colleagues (2008) defined: Knowledge of Content and Students as well as Knowledge of Content and Teaching.

Knowledge of Content and Students "is knowledge of common student conceptions and misconceptions about particular mathematical content" such as "the kinds of shapes young students are likely to identify as triangles" (Ball et al., 2008, p. 401). For example, even students in third grade often believe equilateral triangles oriented with one angle pointed up are valid triangles, whereas they believe the same triangle oriented differently or scalene triangles are not actually triangles (Schifter, 1999). This aspect of knowledge teachers need is about relating their understanding of mathematical ideas with how students think about those mathematical ideas (Ball et al., 2008). Hill and colleagues (2008) defined this kind of knowledge separately from the types of knowledge needed to critique or understand instructional materials as discussed next.

Knowledge of Content and Teaching reflects how well "teachers evaluate the instructional advantages and disadvantages of representations used to teach a specific idea" (Ball et al., 2008, p. 401). This type is about how teachers apply their understanding of mathematics with tools and methods for teaching (Ball et al., 2008). In other words, the kinds of examples of shapes that should be shown in instruction, ways of referring to properties of particular shapes, and the relative affordances and lack of affordances that particular tools such as manipulatives or books offer students are part of Knowledge of Content and Teaching.

As Ball and colleagues (2008) explained, a single teaching scenario or reflection can and likely does reflect multiple aspects of mathematical knowledge for teaching, and where one aspect begins and another ends can be blurred. Consider the anecdote of in-service teachers again in light of this theoretical framework. The in-service teachers had determined that including representations of squares as rectangles would be detrimental to student learning. The conviction that elementary students should not be shown images of squares as part of their developing understanding of rectangle indicated a need to improve (or transform) their Knowledge of Content and Students as well as Knowledge of Content and Teaching. This single idea indicated an outdated understanding of how students think (Knowledge of Content and Students) as well as the representations that would support their learning (Knowledge of Content and Teaching). The colleagues' claims also reflect two myths about early childhood mathematics that impacted their Knowledge of Content and Students and their Knowledge of Content and Teaching, specifically, myths Lee and Ginsburg (2009) identified as "young children are not ready for mathematics education...and simple numbers and shapes are enough" (p. 37). In this report, we describe an activity (the Shape Book Critique Activity) designed to challenge such problematic myths while addressing three aspects of Mathematical Knowledge for Teaching (Common Content Knowledge, Knowledge of Content and Students, and Knowledge of Content and Teaching).

\section{BACKGROUND}

Many years ago, due to the exchange in the anecdote, the first author began looking for reasons that underlie in-service teachers' engrained conceptions about shapes that persisted into adulthood and their teaching careers (i.e., Common Content Knowledge). A search for potential sources led the first author to conduct a content analysis of children's shape-related books as one of the initial incomplete and inaccurate sources of an individual's concept of shapes (Nurnberger-Haag, 2017). If mathematics teacher educators know sources of such conceptions, this might inform how to craft professional development. The first author 
conducted an in-depth content analysis of children's shape books. These data were used in practice for a decade to develop and repeatedly revise the rubric-centered professional development activity reported here to encourage in-service teachers to confront the inaccuracies in published books as a way to develop their Mathematical Knowledge for Teaching, although the content analysis of the books themselves was published only recently (Nurnberger-Haag, 2017). Due to mathematics anxiety, especially among elementary teachers (Rech et al., 1993), an additional challenge for mathematics teacher educators is to find ways to help teachers become aware of long-held inaccurate conceptions in a supportive and empowering way. The activity has three specific goals: a) provide a non-threatening context so that teachers might become aware of their own incomplete or inaccurate conceptions of shapes and improve their Common Content Knowledge of geometric shapes, b) facilitate teachers to recognize that information in such authoritative resources is a likely source of their students' conceptions, thus helping teachers to anticipate their students' conceptions of shapes and understand what students are capable of and need in order to learn geometric shapes, and c) encourage teachers to learn how to critically evaluate shape-related resources such as children's books and develop the disposition to do so before deciding to use such books. Table 1 summarizes how each of these three goals maps onto the theoretical framework of Mathematical Knowledge for Teaching (Ball et al., 2008).

Table 1. Goals of Shape Book Critique Activity Aligned with Mathematical Knowledge for Teaching (MKT)

\begin{tabular}{cc}
\hline MKT Aspect & Activity Goal \\
\hline CCK & Goal 1: Recognize and improve own incomplete and/or inaccurate conceptions of geometric shapes \\
\hline KCS & Goal 2: Recognize and anticipate student conceptions of shapes; understand what students are capable of and need in order to \\
learn geometric shapes
\end{tabular}

\section{Common Content Knowledge of In-Service and Pre-Service Teachers}

As previously described, Common Content Knowledge refers to the knowledge a mathematically competent adult knows regardless of their chosen career (Ball et al., 2008). There is factual knowledge within the discipline of mathematics that can be assessed such as knowing a working definition of a rectangle or being able to identify rectangles from a given set. As opposed to facts, the van Hiele framework for geometric learning (van Hiele, 1986) articulates levels of geometric reasoning of a person's Common Content Knowledge. Due to translations and enhancements over the last seven decades, many synonymous terms are used for the van Hiele levels. Essentially, the sequence of levels is: Prerecognition, Visual or Syncretic, Descriptive, Informal Deduction, Formal deduction, and Rigor (Burger \& Shaughnessy, 1986; Clements et al., 1999; van Hiele, 1986, 1999). Van Hiele, a contemporary of Piaget, assertively distinguished that the levels of geometric thinking are experiential levels rather than the developmental levels of Piagetian theory (van Hiele, 1986). In other words, although the initial van Hiele levels are most typically found in young children, young children are capable of learning to reason through progressively more difficult levels sometimes surpassing adults who have not had the same learning opportunities (Clements et al., 1999; van Hiele, 1986). It is crucial to understand that these levels are levels of reasoning with and about geometry rather than discretely memorized facts about geometry (van Hiele, 1986).

The Prerecognition level was an extension of the van Hiele framework to ensure the framework could include the reasoning levels typical of the youngest children who do not yet for example understand that there are things called shapes or who might overgeneralize to call all shapes by the one shape they have visually memorized (e.g., circles or triangles; Clements et al., 1999). Visual level thinking was the lowest level defined by van Hiele, which reflects reasoning that matches a visual template or idea of what a shape is from prior experience to identify whether the shape provided to them is that shape (van Hiele, 1986). At this level the articulation in words as to why that shape is the named shape is limited to statements such as "it just is" or "it looks like one" as a learner "verbally describes shapes by their appearance as a whole" (Fuys et al., 1988, p. 34, p. 59). The Syncretic level means that a learner uses visual matching from prior experiences along with some insufficient property information to identify a shape, such as it looks like a rectangle because it has four sides (Burger \& Shaughnessy, 1986; Clements et al., 1999). The Descriptive level of reasoning consists of a thorough understanding of all the properties that are true for a shape and an ability to talk about these (van Hiele, 1986). This does not yet mean, however, that the learner has consolidated and determined how shapes or properties relate to each other. Such reasoning is characterized as the Informal Deduction level of reasoning or sometimes called Relational level (Kutluca, 2013; van Hiele, 1986). At this Informal Deduction or Relational level, the learner is not yet able to use the formal language and structures required in proofs to explain and justify a theorem, for example, but they demonstrate deductive reasoning using their own informal language to explain their reasoning (van Hiele, 1999). At this level the learner could use definitions of shapes to explain using their own words why every square also has to be a rectangle. Reasoning at this level is crucial to success in a formal high school geometry course (van Hiele, 1986). Current standards in the United States expect students to reason at this informal deduction level by the end of Grade 5 (Common Core State Standards, 2010/2015).

The levels of Formal Deduction and Rigor are beyond the levels of reasoning relevant to this study, so we only briefly describe these. Formal deduction is the level of reasoning required for learners to successfully use formal axioms, definitions, postulates and theorems to prove other theorems in a secondary geometry course (van Hiele, 1986). Rigor relates to the work of the discipline of mathematics in which people are able to simultaneously understand and compare the axiomatic systems and subsequent theorems of different kinds of geometry such as Euclidean Geometry or Non-Euclidean Geometry (van Hiele, 1986). Although teachers must at least reason at the level of formal deduction to facilitate student discussions of the implications of varied definitions (Association of Mathematics Teacher Educators [AMTE], 2017; de Villiers, 1994), studies of elementary, middle, and high school PSTs found that about one-fifth of PSTs were reasoning at a van Hiele level lower than expected of students in elementary school (Halat, 2008a, 2008b). 


\section{Teachers' difficulties with 2D shapes and distinguishing from 3D shapes}

Many PSTs and in-service teachers have difficulties with 2D shape knowledge at the secondary and elementary school levels (Millsaps, 2013; Pytlak \& Swoboda, 2017; Tsamir et al., 2015; Van der Sandt \& Nieuwoudt, 2003). Such difficulties are due to the dominance of visual level reasoning based on prototypical images (i.e., those images memorized through frequent exposure) without considering properties (Fujita, 2012; Millsaps, 2013; Ozdemir Erdogan \& Dur, 2014; Pytlak \& Swoboda, 2017).

A literature search for teachers' knowledge of triangle yielded just one study (i.e., Tsamir et al., 2015). This study found that almost one-fifth $(17 \%)$ of the early-year Israeli teachers identified triangles based on prototypical images such that they were unable to distinguish between triangles and non-triangles (Tsamir et al., 2015). Adults' definitions of rectangles also typically rely on limited properties that are valid only in prototypical images such as "a quadrilateral which has 2 longer sides and 2 shorter sides" (Fujita, 2012, p. 61; Pickreign, 2007; Turnuklu et al., 2013). Standards for teaching future educators have referred to this operating definition as "completely inadequate" (AMTE, 2017, p. 52). According to AMTE (2017), teachers "need to understand geometry deeply enough to guide discussions of different informal definitions" (p. 52) and understand the efficiency and reasons for choosing different definitions (de Villiers, 1994). Yet, as van Hiele (1986) emphasized, instruction must meet learners at their current reasoning level to facilitate progression to higher levels. In other words, when people reason at the visual or descriptive level they would not be able to learn from activities that require formal deduction level reasoning (van Hiele, 1986). They may be able to memorize facts valid with such reasoning levels such that they might appear to be at the higher level, but this does not reflect true understanding at these levels (van Hiele, 1986). Thus, PSTs must be provided experiences to progress through such levels. Regardless of whether the learners are children, adolescents or adults, van Hiele emphasized that experience is the key of progressing through the levels (van Hiele, 1986). Hence, mathematics teacher educators must not only meet PSTs at their current level of reasoning, but also be aware of the ubiquity of prototypical conceptions and memorized inaccuracies caused by inaccurate sources of information such that even when people are able to reason at higher van Hiele levels the incomplete and prototypical ideas of shapes they have believed since childhood conflict in ways that often supersede their reasoning (Pytlak \& Swoboda, 2017). In other words, PSTs must choose whether to believe the facts they have known throughout most of their lives taught by trusted sources (Nurnberger-Haag, 2018) or trust their reasoning that contradicts such facts. Such prototypical images portray partitive definitions that make it difficult for PSTs and in-service teachers world-wide to accept hierarchical relationships of quadrilaterals (Fujita, 2012; Fujita \& Jones, 2007; Luneta, 2014; Marchis, 2012; Ozdemir Erdogan \& Dur, 2014; Pytlak \& Swoboda, 2017; Turnuklu et al., 2013). For instance, just $13 \%$ of elementary PSTs in Scotland and $46 \%$ of elementary PSTs in Turkey accepted squares as rectangles (Fujita \& Jones, 2007; Ozdemir Erdogan \& Dur, 2014).

Most studies have focused exclusively on 2D shapes, and thus failed to capture conflation of 2D and 3D. Even those studies designed to include both 2D and 3D shapes assessed these shapes separately (e.g., Tsamir et al., 2015). However, the one study in which PSTs were asked to "Draw and name five 2-dimensional shapes," and repeated this request for 3D shapes, revealed that $63 \%$ of PSTs struggled to tell the difference between 2D and 3D (Luneta, 2014).

\section{Common Content Knowledge of Geometric Shapes Children's Books Portray}

Although children's books are increasingly promoted for mathematics learning, there is little rigorous research evidence that such instruction is effective (Flevares \& Schiff, 2014). Moreover, when researchers intend to determine the efficacy of using children's books to improve mathematics learning, they should rigorously critique the books' mathematics content prior to use, which so far has been uncommon (Flevares \& Schiff, 2014; Nurnberger-Haag, 2017, 2018; Nurnberger-Haag et al., 2019; Nurnberger-Haag, Alexander \& Powell, 2021). In a content analysis of the mathematical quality of 69 children's books about shapes, about half conflated 2D and 3D shapes, and 76\% showed or stated an inaccuracy about 2D shapes (Nurnberger-Haag, 2017). These books primarily portrayed triangles at the visual level using acute-isosceles or equilateral images (Nurnberger-Haag, 2017). With regard to quadrilaterals, most children's books implicitly and explicitly used the partitive definition of rectangle and four sides was often the only stated property of rectangles (Nurnberger-Haag, 2017). Moreover, almost half of the books that stated some property of rectangles indicated that two sides must be longer (Nurnberger-Haag, 2017). Thus, the first purpose of the activity reported in this study was not to promote using such books to teach children, but to use these inaccurate children's resources to improve PSTs' Common Content Knowledge (Goal 1).

\section{Teachers Need to Know What Children Can Do and Have the Disposition to Use this Knowledge to Critically Choose Representations for Instruction}

Mathematics teacher educators have the dual work of providing elementary grades PSTs with experiences designed to improve their Common Content Knowledge, while also ensuring that PSTs have sufficient Knowledge of Content and Students and Knowledge of Content and Teaching to provide their (future) students with learning experiences at least at the descriptive van Hiele level. PSTs need Knowledge of Content and Students to understand and anticipate their students' prior knowledge, including students' incomplete or inaccurate conceptions of shapes. An example would be knowing that children will likely call a ball a circle. A common myth held by teachers is that young children cannot handle rigorous mathematics (Lee \& Ginsburg, 2009). For such teachers, prototypical shapes provided to their students at the visual level are sufficient and developmentally appropriate (Lee \& Ginsburg, 2009). Yet, the van Hiele reasoning levels are experiential not developmental, so with the appropriate experiences young children could learn to reason at higher levels than even some adults (Clements et al., 1999; van Hiele, 1986). Beginning in kindergarten, current standards (Common Core State Standards, 2010/2015) seek to address these early childhood myths by informing teachers that instruction should begin with children describing and learning properties; that is, at the descriptive level (van Hiele, 1986). Moreover, teachers should develop a critical eye for potential sources of those conceptions and what students entering their classroom are likely to think. Furthermore, knowing how to choose representations for instruction 
to counteract such prior informal influences is crucial to develop as part of PSTs' Knowledge of Content and Teaching (Ball et al., 2008; Flevares \& Schiff, 2014; Yilmaz Genc et al., 2017).

\section{METHOD}

With this study we investigated the efficacy of an activity (i.e., the Shape Book Critique Activity) in which PSTs used a rubric to critique shape information in children's books as part of their course at a large public U.S. university. PSTs in the U.S. typically take required mathematics content courses early in their bachelor's degree program. Near the end of their 4- to 5-year degree, PSTs take at least one methods course focused on how to teach mathematics. We collected data in both a content course in the mathematics department and a methods course for mathematics in the education department. For this exploratory study we collected data using a post-test only design due to two reasons: time constraints within instructors' classes and an effort to avoid potentially activating PSTs' math and/or test anxiety. With regard to time constraints, neither the methods course nor the content course typically used class time to give PSTs pre-assessments of content knowledge. Typical assessments in the content course consisted of unit tests and the final exam, so even the use of the post-activity assessment reported here required additional investment of class time compared to typical practice. The methods course did not typically assess Common Content Knowledge. Moreover, the Shape Book Critique Activity was intended to provide a safe and inviting way for PSTs to discover and reflect on their Common Content Knowledge of geometric shapes instead of a typical test-based approach. We were concerned that a preassessment might trigger PSTs' mathematics anxiety and/or test anxiety (Harper \& Daane, 1998; Rech et al., 1993), which has been shown to negatively correlate with geometry performance (Novak \& Tassell, 2017). Thus, although as researchers we prefer a prepost design, for these reasons, we implemented a post-assessment design for this first study on PSTs' responses to the ShapeBook Critique Activity. Data collection consisted of an instructor reflection that focused on how the activity was implemented, and two immediate post-activity measures: Opinion Survey and Content Test.

\section{Context, Instructors and Participants}

One instructor in the mathematics department used the Shape Book Critique Activity with the two sections of her mathematics content course for PSTs, and one instructor in the education department implemented the activity with all four sections of the early childhood mathematics methods course. Both instructors had been mathematics educators for at least 20 years and have doctoral degrees. At the time of data collection, the content course instructor had been teaching university mathematics for 23 years and for the last 16 years had been teaching content courses for PSTs. These data were collected after the content instructor's first experience implementing the Shape-Book Critique Activity. The methods course instructor's (first author) relevant experience included teaching methods courses for 4 years across grade bands at three universities, 1.5 years teaching mathematics content courses and developmental mathematics (a.k.a. remedial mathematics) at the college level, high school geometry for 6 years, and extensive experience offering professional development to teachers. Although over the prior 10 years, the methods course instructor had developed and implemented the activity countless times with in-service teachers and PSTs, this was the first-time data were collected and systematically analyzed to judge the activity's efficacy.

Each instructor implemented the Shape-Book Critique Activity with all PSTs in their course sections during a single academic year. Immediately after completing the activity, each PST completed the survey and content test so that the instructors could use this information as formative assessments (i.e., to inform their subsequent instruction on geometry).

Students in the content course were primarily PSTs in Early Childhood (preschool to Grade 3), Middle Childhood (Grades 4-8), or Special Education (Grades K-12). About five weeks after PSTs completed the activity and the survey/content test, each of the two course sections was visited by a member of the research team to request student participation in the study. PSTs provided their anonymized surveys to the researcher, with a rate of research participation in the content course of $70.5 \%(n=55)$. All PSTs in the early childhood methods course participated in the Shape-Book Critique Activity during the third class of the semester. At the end of the semester another member of the research team came to the class to request use of their anonymized surveys for the study. Across the four sections of the methods courses, $92.8 \%(n=78)$ of PSTs participated in the research. Gender, major, and other identifying information were not collected.

\section{Shape Book Critique Activity Instruction}

It is crucial that teacher educators help PSTs and in-service teachers develop a critical lens toward any potential material considered for instruction (Flevares \& Schiff, 2014; Yilmaz Genc et al., 2017). This competency and disposition is part of Knowledge of Content and Teaching (Ball et al., 2008). What people notice about the potential efficacy of children's books, however, depends on their content knowledge (Nesmith \& Cooper, 2010). In-service teachers' and PSTs' typical Common Content Knowledge conceptions are consistent with the incomplete and inaccurate portrayals in children's books (Nurnberger-Haag, 2017). These findings sparked the idea to provide in-service teachers with a critical lens to focus on the geometry in children's books in the hope that such activities would encourage them to become critically reflective of their own potentially similar conceptions. Thus, to address the three stated goals (i.e., improve their own content knowledge, anticipate and support student understanding, critically analyze and select children's books) for improving the Mathematical Knowledge for Teaching of in-service teachers and PSTs, the first author developed a rubric-based activity for educators to evaluate children's shape-related books. The rubric (see Appendix A) was developed through content analyses of shape-related books (Nurnberger-Haag, 2017) and repeatedly revised over the course of a decade-as a result of its use with in-service teachers in professional development and PSTs in methods courses. The rubric was designed to provoke in-service teachers and PSTs to grapple with the validity of several Common Content Knowledge-related ideas (e.g., a rectangle does not have to be oblong) as they apply it to children's books. The rubric also includes 
Knowledge of Content and Teaching-related ideas about selecting representations (e.g., a single prototypical representation of a shape would mislead their students' conceptual development of shapes).

Prior to class each instructor assigned two to three articles from the National Council of Teachers of Mathematics publication Teaching Children Mathematics (specified in Appendix B) for PSTs to read at home. During class small groups of PSTs used the rubric for about 20 minutes to critique one or more books. Next, each instructor led a 20-minute whole class discussion during which PSTs shared and discussed relevant pages of the book on a document camera. Both instructors listened to ideas shared during small group discussions to determine which students should share their books to ensure the discussion included several key issues (i.e., orientation is not a defining attribute of shapes, 2D/3D conflation, misconception of rectangles being oblong, rhombuses and parallelograms can have right angles, and the problem for student learning if only prototypical images are used). The specific prompts that each instructor used to initiate the activity, and other similarities and differences in instructors' implementation, are provided in Appendix B. Differences included that PSTs in the methods course were required to bring to class a shape-related book (obtained from local libraries, field placements, and other sources), but the content instructor obtained the books for her class to use from a local library. Another difference was that in the methods course pairs of students discussed the books each of them brought, whereas in the content course three to four students discussed a single book. Documentation of the books used (i.e., book titles) was not part of data collection.

\section{Data Sources and Analysis}

Data sources consisted of a post-activity opinion survey with three open-response questions and a content assessment.

\section{Opinion survey}

The three open-response survey questions asked the PSTs to report whether this was a valuable activity for their learning and why:

1. How, if at all, did evaluating children's books with the given rubric improve your own knowledge about shapes? [This question is about your mathematics content knowledge, not how to teach it. Please be as specific as possible and provide as much explanation as you can.]

2. In what ways might this activity of evaluating children's books change how you will talk with children about shapes (either children you care about now or in the future)?

3. What did evaluating children's books with the given rubric help you learn about children's shape learning and how you would plan learning experiences in the future? Please explain as many ideas as you can.

The research team first coded whether PSTs' responses to any of the three questions indicated the activity was beneficial in any of the following ways: a) improving their own content knowledge, b) changing how they would talk with children about shapes, c) changing their understanding about what children know or how they learn about shapes, and d) changing how they would plan learning experiences in the future. We began with codes of "agree," "disagree," and "left blank," then developed additional sub codes and same level codes to capture data that did not fit these categories. For example, the refresh and conflicting evidence codes were added due to nuances found in PST responses for agree and disagree, respectively (see Appendix C for coding schemes).

Next, members of the research team independently read all narrative answers to the open response survey questions to suggest other potential themes. From these initial interpretations, with the intent of each question and the research goals in mind, two additional coding schemes were developed to ensure that every participant's response could be characterized by exactly one of the codes in each scheme (see Appendix C for coding schemes.). One prominent theme was PSTs' surprise that resources such as children's books could be inaccurate. Another prominent theme was PSTs' indication of properties and visuals. Thus, although the original research goals and question prompt did not specifically seek to assess van Hiele levels of PSTs' thinking, a coding scheme was developed to interpret PSTs' spontaneous expression of these ideas in relation to how they perceived the Shape Book Critique Activity would change their instruction.

One researcher served as the primary coder and another member of the research team coded $20 \%$ of randomly selected PSTs for each coding scheme to determine inter-rater agreement. Given that coding 10-15\% of the data for inter-rater agreement is a commonly accepted research standard (Riazi, 2016, p. 151), coding 20\% of these data was a more rigorous approach. The data of the primary coder are reported for those coding schemes with Cohen's Kappa (a more rigorous inter-rater agreement measure) above 0.80 -which suggests almost perfect agreement (Landis \& Koch, 1977)-and percent agreement above $87 \%$. To assess the interpretation of van Hiele levels that PSTs expressed in their responses, consensus coding with two coders was used.

Given the focus on teaching practice and the nature of the data, after coding was complete, we generated a word cloud to reveal the most frequent 100 words participants used in their responses (Figure 1). We removed common words (e.g., the, $a$, because) and any words from the questions themselves that participants restated in their responses (e.g., children, shape, book, student). All references to dimensionality, such as 2D, 3-D, and 2-dimensional, were replaced with two-dimensional and threedimensional for consistency and because the program ignored numerals and hyphens. The word cloud display was consistent with our close reading of the 397 survey responses, so we provided the word cloud as a visual summary of the PSTs' perceptions (see DePaolo \& Wilkinson, 2014).

\section{Content test}

Mindful of the time constraints in these courses, the Content Test consisted of two multi-part questions to assess PST identification of two polygons. PSTs were asked to select correct images of rectangles among quadrilaterals and to assess triangles by crossing off those that were not triangles. These tests were based on items used in prior studies (Clements \& Battista, 1991; 
Schifter, 1999). The established rectangle assessment used in prior research (Clements \& Battista, 1991) omitted 3D distractors, but included 11 distractor items of concave and convex quadrilaterals without right angles, and four valid rectangle items that varied by dimension including a horizontally oriented square and rotated square. We created the triangle measure by adding three 3D images (tree, slice of pizza, and party hat) and one 2D distractor (concave quadrilateral known as a chevron) to eight triangles from Schifter's (1999) task. Each item of the rectangle task and triangle task, respectively, were coded as 1 for accurate or 0 for inaccurate. The task was considered accurate only if all valid rectangle or triangle items were 1 and all invalid items were 0. Descriptive statistics of participant accuracy on these two tasks are reported.

\section{RESULTS}

We report the results of how 133 PSTs responded to the experience of critiquing a children's shape-related book using the rubric in Appendix A. Prior to reporting how well the activity addressed the three aspects of Mathematical Knowledge for Teaching, we provide an overview of PSTs' perceptions based on the 397 survey responses that were collected. To do so, we display PSTs' responses using a word cloud of the most frequent 100 words they used when responding to the survey questions that asked how, if at all, the activity had changed a particular aspect of their thinking or intentions (Figure 1).

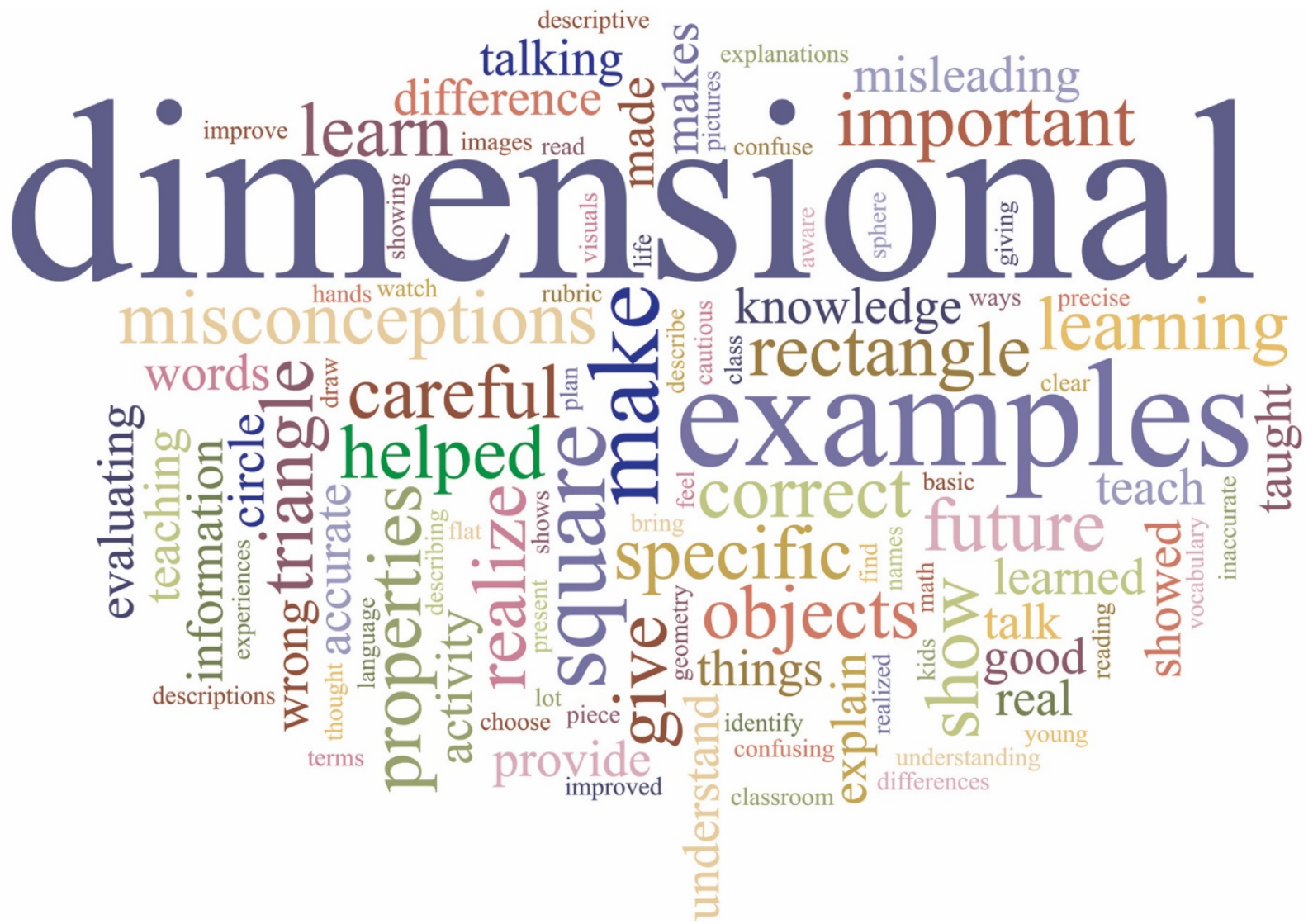

Figure 1. Visual Representation of the Relative Frequencies of the Most Prominent 100 Words in PSTs' Survey Responses about the Value of the Activity

By visually displaying word frequencies, word clouds provide a helpful starting point for the reader to make sense of patterns in large sets of textual data (DePaolo \& Wilkinson, 2014). Because we agreed that this representation in Figure 1, generated after our qualitative analyses, was consistent with our close reading of the data, we chose to present the PSTs' words in this visually succinct format. We display representative responses in which the PSTs used the words (bolded) to communicate the context in which such words were typically used.

- By having to think about triangles and their properties, it helped me to realize that some shapes I thought could be labelled as triangles actually are not.

- This activity made me value the knowledge teachers need to know about shapes in order to accurately teach children. This made me realize how important it is to watch what you say to children so they don't form misconceptions about shapes.

- ... a sign is a prism no matter how flat, and a square is a rhombus with 4 right angles.

- It helped show how things need to be said. Have to show multiple examples of foot prints of objects and not give 2D names to 3D objects. Also shows how precise you have to be when giving directions on how to draw a shape. Show how often shapes could be "the same"--rectangle could be a square.

- I learned that just how precise you have to be. In order to correctly teach your children. I also learned the importance of having a wide variety of examples. Differentiating between 2D and 3D names is also extremely important.

- This makes me more cautious... I know to be exact with properties and characteristics. 
We provided these examples to communicate trustworthiness as to how the PSTs meant these words that were prominent in the word cloud.

\section{Impact of Activity on PSTs' Common Content Knowledge}

To assess PST shape understanding in terms of Common Content Knowledge, the rectangle and triangle identification task results are reported. Assessing PST reasoning levels in terms of the van Hiele framework was beyond the scope of this study, but their disposition to teach at certain reasoning levels is discussed in the results for knowledge specific to teaching.

\section{Rectangle identification task}

The rectangle content question was designed to assess PSTs' conception of rectangle among other quadrilaterals without four right angles. A little more than half of PSTs (i.e., 57.3\%) accurately identified all rectangles including long skinny rectangles, a horizontally-oriented square and a square rotated 45 degrees (colloquially in children's books this is often referred to as a diamond; Nurnberger-Haag, 2017). Inspection of this data by course found 36 PSTs (66.7\%) in the content course and 39 PSTs $(50.6 \%)$ in the methods course accurately identified all rectangles. Non-parametric Mann-Whitney $U$ test found no significant differences by course type on overall accuracy.

\section{Triangle identification task}

More than three fourths of PSTs (77.9\%) correctly identified images that were triangles among non-example distractors by crossing out all images that were not triangles. With regard to the common error of identifying triangles from a visually approximate shape rather than by properties (Fujita, 2012; Schifter, 1999), 7.8\% misidentified the concave quadrilateral as a triangle. At least one 3D image (i.e., slice of pizza, pine tree, or cone-shaped party hat) was selected by $15.2 \%$ of PSTs. Content course accuracy on the triangle task was $75.9 \%$ and method course accuracy $77.9 \%$. Again, non-parametric Mann-Whitney $U$ tests confirmed the differences in accuracy between course types were not significant.

\section{PSTs' perceptions of the impact of Shape Book Critique Activity on their Common Content Knowledge}

Table 2 reflects PSTs' perceptions of how well the Shape Book Critique Activity improved their Common Content Knowledge and if the activity encouraged them to recognize their own incomplete or inaccurate shape knowledge. More than half of PSTs (52.6\%) agreed that evaluating a children's book with the given rubric improved their content knowledge about shapes (code Explicit) or that the activity reminded them of their forgotten knowledge (code Refresh).

Table 2. Survey Responses Indicated Whether PSTs Perceived That the Shape Book Critique Activity Improved Common Content Knowledge

\begin{tabular}{|c|c|c|c|c|c|c|}
\hline \multirow[b]{2}{*}{ Course Type } & \multicolumn{2}{|c|}{ Agree } & \multicolumn{2}{|c|}{ Inconclusive } & \multicolumn{2}{|c|}{ Disagree } \\
\hline & $\begin{array}{c}\text { Explicit } \\
\%\end{array}$ & $\begin{array}{c}\text { Refresh } \\
\%\end{array}$ & $\begin{array}{l}\text { Insufficient } \\
\text { Evidence \% }\end{array}$ & $\begin{array}{l}\text { Conflicting } \\
\text { Evidence \% }\end{array}$ & $\begin{array}{c}\text { Explicit } \\
\%\end{array}$ & $\begin{array}{c}\text { Omit } \\
\%\end{array}$ \\
\hline Content & 36.4 & 9.1 & 25.5 & 9.1 & 16.3 & 3.6 \\
\hline Method & 50 & 7.7 & 38.4 & 1.3 & 2.6 & -- \\
\hline Total & \multicolumn{2}{|c|}{52.6} & \multicolumn{2}{|c|}{37.6} & \multicolumn{2}{|c|}{9.8} \\
\hline
\end{tabular}

\section{PSTs who agreed the activity improved their Common Content Knowledge}

The survey question asked generally if the activity impacted their Common Content Knowledge and also requested specific examples of how the activity influenced their Common Content Knowledge. Next, we provide 10 representative quotations from the $52.6 \%$ of PSTs whose responses we coded as agreeing that the activity improved their Common Content Knowledge (coded as Explicit or Refresh). These quotations are organized to discuss the ways in which PSTs reported their knowledge changed. First, we report general acknowledgement of their own misconceptions or improvement. Then we report the themes we found PSTs gave as the specific ways their knowledge improved: realization they should not rely on visual level understanding of shapes because at least descriptive level reasoning is required (e.g., properties, precise); correction of 2D/3D conflation; and a hierarchical understanding of the square-rectangle relationship.

Note that phrases such as "showed me...my knowledge is not what it should be," "helped to improve," "it definitely clarified," and "it taught me" in the first four quotations state the impact on their Common Content Knowledge due to the activity.

- Evaluating the children's books with the given rubric showed me that my knowledge is not what it should be.

- It helped to improve my own knowledge of shapes by really focusing on the properties and not just the visual images.

- It definitely clarified my perception of what these shapes really are. It enhanced or helped me make the connection back to my previous learning with geometry. For example, talking about the specific properties (square is rectangle, etc.).

- It taught me that you need more than just examples of shapes, but you also need to know what makes a shape, the shape it is.

Note that in addition to the above four quotations explaining that the PSTs perceived that their Common Content Knowledge improved, the last three quotations also specifically explained that a way their knowledge improved was because they now understand they should not rely on "just the visual images" and "just the examples," but "properties" or "know what makes a shape, the shape it is."

Next, we selected three typical responses of PSTs who recognized that the activity improved their Common Content Knowledge by correcting their conflation of $2 \mathrm{D}$ and $3 \mathrm{D}$.

- It helped me to realize that real life items are not 2D shapes and that I can't just call a book a rectangle. 
- You may be able to create a footprint on that 3D object to make a specific shape but 3D objects are not equal to 2D shapes.

- I realized that I am not as specific at identifying properties of shapes or using the 2D and 3D names separately. There are also some properties that I have forgotten.

The last quotation is an example of a response that contained more than one way the PST recognized their common content knowledge improved: the elimination of 2D/3D conflation and the importance of properties. The next three quotations were typical responses of PSTs whose knowledge of rectangles transformed to a hierarchical understanding.

- Making sure I am correct when clarifying that a rectangle isn't necessarily something with 2 sides long and 2 short because a square can be a rectangle too.

- Rectangle cannot be described as 2 long, 2 short sides. Many incorrect representations: made me realize most books I used as a child were mathematically incorrect.

- I didn't really know that a square was a rectangle so it improved my knowledge that way and also show me to be precise with how I represent a rectangle.

It is a crucial consideration of our practice as mathematics teacher educators to anticipate and uncover our own students' thinking in relation to our activities. Thus, it is important to note that a few PSTs reported in their responses improved understanding in a way that revealed the activity as implemented corrected some inaccuracies, yet new inaccuracies might have been created. Consider this quotation as an example. In the first sentence the PST confirmed that the activity broadened their knowledge of shapes in general with the phrase "a lot more to understanding shapes," yet we must consider the specific example the PST used to explain this idea.

That there is a lot more to understanding shapes than I had originally thought. Rectangle vs. square. Don't need two equal sides, square is rectangle, rectangle is a square.

In this example, the PST accurately explained that a rectangle need not have two opposite sides that are equal lengths and different lengths than the other sides; however, this PST also incorrectly stated that every rectangle is also a square.

\section{Responses inconclusive about impact on Common Content Knowledge}

In Table 2, Insufficient Evidence and Conflicting Evidence codes comprise the set of responses we described as Inconclusive Evidence about the impact on Common Content Knowledge, which accounted for $37.6 \%$ of the PSTs.

The Insufficient Evidence code (see Appendix C) documented PSTs who rather than reflecting on their own content learning as the survey question asked, instead responded about their future students or the accuracy of the books. For instance, the statement coded as Insufficient Evidence "Not everything you read in a book is right. I would show that to my class." reflects important learning related to Knowledge of Content and Teaching. However, even though the survey question specifically asked PSTs to reflect on their own Common Content Knowledge, the response did not address this, so there was insufficient evidence about this PST's perception of the impact of the activity on their Common Content Knowledge (See Table 2 for descriptive statistics by course type).

We developed the Conflicting Evidence code (see Appendix C) to account for another way in which PSTs provided inconclusive evidence about the impact of the shape book critique on their Common Content Knowledge. The Conflicting Evidence code was used if the PST first explicitly stated the activity did not improve their content knowledge, but then proceeded to explain an aspect of Common Content Knowledge they had learned due to the activity (see Table 2 for descriptive statistics by course type). These three PST responses reflect typical answers under this code in which the elements of their response conflicted with each other.

- It did not really improve my knowledge. I have previously learned almost everything that was in the book, except for names of larger, multisided polygons.

- This book didn't improve my mathematics knowledge but it showed me that I need to be careful what shape I call objects because many are not actually the shape. For example, a box is not a square.

- I think that I knew about the shapes already but the rubric made it clear that a square is a rectangle, there are multiple types of triangles and 3-D objects cannot be 2-D shapes.

We interpreted these responses as meaning that the PSTs perceived at a general level that the activity did not improve their shape knowledge, yet they offered specific ways in which using the activity actually had transformed their Common Content Knowledge. The PST in the first quotation acknowledged that the activity led to learning the names of "multisided polygons." The last two PSTs claimed they did not need to improve their knowledge in spite of the fact that two-dimensionality is one of the defining properties of polygons, but then they indicated that due to the activity they now know the difference between 2D and 3D shapes. Moreover, although the third PST claimed that they "knew about the shapes already" their response revealed three specific concepts that they previously may not have understood (i.e., a square is a type of rectangle, variety of triangle types, and 2D shapes differ from 3D shapes).

\section{PSTs who disagreed that the activity impacted Common Content Knowledge}

Only 9.8\% (see Table 2) of PSTs disagreed that the Shape Book Critique Activity improved their Common Content Knowledge. A sample response of PSTs who explicitly Disagreed, possibly due to having strong Common Content Knowledge of geometric shapes, was: "It didn't improve my knowledge of shapes. I understand the whole 2D/3D and different properties." Other responses, however, revealed a flaw of implementation and therefore provided insight about how to improve the activity: "The book we evaluated only involved triangles...It did not improve my knowledge about triangles." We interpreted such comments as meaning that had the book included quadrilaterals or other polygons the PSTs might have Agreed that the activity improved their knowledge. Rather than considering omitted responses as inconclusive evidence, we chose to apply a more conservative coding 
approach such that when PSTs avoided answering the question that targeted Common Content Knowledge, we coded this lack of response as the PST disagreeing that the activity improved this type of knowledge (see Omit in Table 2).

\section{Changes in Knowledge Specific to Teaching}

Most PSTs reported that the Shape-Book Critique Activity changed how they will talk with children (97.7\%), helped them learn about children's shape knowledge ( $83.5 \%$ of PSTs), and prepared them to plan better learning experiences in the future ( $92.5 \%$ of PSTs). Question 3 included two parts: what they learned about child knowledge (Knowledge of Content and Students), and how the activity influenced how they would plan instruction (Knowledge of Content and Students and Knowledge of Content and Teaching). Some PSTs answered one but not both parts of this question, which led to inconclusive evidence codes (16.5\% and $7.5 \%$, respectively). For instance, one PST responded with the statement: I will be careful and watch for the words I use, the books I share, and the examples I give to demonstrate shapes. Thus, this PST provided three types of representations they will carefully select for instruction, which reflected their growth in Knowledge of Content and Teaching: words, books, and examples. One might infer that because this PST would make such instructional choices, the PST also gained knowledge about how students are likely to think (Knowledge of Content and Students); however, the PST did not state explicit information about what students think to answer that part of the question. Table 3 displays the percent of PSTs whose responses were coded using the coding scheme in Appendix C.

Table 3. Degree of Agreement for PSTs Perception of the Value of the Activity for Developing Knowledge Specific to Teaching

\begin{tabular}{|c|c|c|c|c|c|c|c|}
\hline \multirow{2}{*}{$\begin{array}{c}\text { Survey } \\
\text { Questions }\end{array}$} & \multirow{2}{*}{$\begin{array}{l}\text { Course } \\
\text { Type }\end{array}$} & \multicolumn{2}{|c|}{ Agree } & \multicolumn{2}{|c|}{ Inconclusive } & \multicolumn{2}{|c|}{ Disagree } \\
\hline & & $\begin{array}{c}\text { Explicit } \\
\% \\
\end{array}$ & $\begin{array}{c}\text { Refresh } \\
\% \\
\end{array}$ & $\begin{array}{c}\text { Insuff. Evidence } \\
\% \\
\end{array}$ & $\begin{array}{l}\text { Conflicting } \\
\text { Evidence \% } \\
\end{array}$ & $\begin{array}{c}\text { Explicit } \\
\% \\
\end{array}$ & $\begin{array}{c}\text { Omit } \\
\%\end{array}$ \\
\hline \multirow{3}{*}{$\begin{array}{c}\text { Changed How Will Talk } \\
\text { with Children }\end{array}$} & Content & 96.4 & 1.8 & 1.8 & -- & -- & -- \\
\hline & Method & 94.8 & 2.6 & 2.6 & -- & -- & -- \\
\hline & Total & \multicolumn{2}{|c|}{97.7} & \multicolumn{2}{|c|}{2.3} & \multicolumn{2}{|c|}{--} \\
\hline \multirow{3}{*}{$\begin{array}{c}\text { Better Understands } \\
\text { Children's Knowledge or } \\
\text { Learning Needs }\end{array}$} & Content & 69.1 & -- & 30.9 & -- & -- & -- \\
\hline & Method & 89.7 & 3.9 & 6.4 & -- & -- & -- \\
\hline & Total & \multicolumn{2}{|c|}{83.5} & \multicolumn{2}{|c|}{16.5} & \multicolumn{2}{|c|}{--} \\
\hline \multirow{3}{*}{ Changed How Will Plan } & Content & 89.1 & -- & 10.9 & -- & -- & -- \\
\hline & Method & 93.6 & 1.3 & 3.8 & 1.3 & -- & -- \\
\hline & Total & \multicolumn{2}{|c|}{92.5} & \multicolumn{2}{|c|}{7.5} & \multicolumn{2}{|c|}{--} \\
\hline
\end{tabular}

We use the following two sample responses to show how typical PSTs responded if they answered both parts of the question:

- Children's shape learning is way more complex than what I first thought \& it is very important to not be misleading. In the future, I will explain why certain shapes are the way they are. I will not generalize a shape, instead I will be very specific about the different types of shapes

- Shape learning is going to be a difficult topic to teach with so many inaccurate books the kids will be exposed to. I will need to be sure to go through books in my class for accuracy.

The first quotation begins with ideas related to Knowledge of Content and Students due to the statement about students: "children's shape learning is way more complex than what I first thought." The rest of the response reflects Knowledge of Content and Teaching in terms of representations appropriate for instruction that are "not... misleading" and the need to "be very specific" and use "different types" of representations. The second quotation also begins with demonstrating Knowledge of Content and Students in the first sentence (i.e., ... difficult topic to teach with so many inaccurate books the kids will be exposed to), which we interpreted as reflecting that the PST gained understanding of what their future students will likely think and sources of those ideas, reflecting gains relative to Knowledge of Content and Students. The PST then followed this with a sentence (I will need to be sure to go through books in my class for accuracy), which indicated that the PST developed the disposition to critique books considered for instructional resources, which demonstrates growth in Knowledge of Content and Teaching.

\section{How activity changed PSTs' ability and disposition to critically choose representations}

PSTs often expressed surprise that published materials about geometric shapes could be inaccurate and indicated that they now understand what children might understand about shapes because of such resources when entering their classes. The survey questions asked PSTs how, if at all, the activity changed how they would plan instruction. With this open-ended prompt, a majority of the PSTs (59.1\%) reported that due to the shape-book critique they realized that children's informal resources can be an inaccurate source for shape learning, and, therefore, such resources need to be carefully selected. This theme was not found in the remaining $40.9 \%$ of PSTs' responses, so these were coded as No Evidence. We noticed that those PSTs who had included the theme in the open-ended prompt about how this would change their instruction, varied by the type of resource they discussed and how broadly they applied this new knowledge to teaching shapes or teaching mathematics more generally, so we developed the coding scheme Recognition That Resources Are Not Always Accurate (see Appendix C) to characterize each PST's responses with a single code. This theme about choosing representations for instruction demonstrates that PSTs reported the activity facilitated growth in their Knowledge of Content and Teaching for geometric shapes.

Specifically, $54.1 \%$ of the PSTs explained that the activity provided new understanding that shape-related books could be inaccurate. The next six quotations are typical responses of those PSTs who discussed the quality of books that teach shapes:

- I never thought about critiquing books before this activity. I always thought that they were reliable because they were published. I now feel more knowledgeable about what to look for in books.

- Showed me to be very careful to previous or future exposure my students have already/ will encounter. 
- It will help me distinguish what is a good book to keep in my classroom and what shows misconceptions.

- This helped me see that just because a book is about shapes, does not mean it will help teach children about shapes.

- It really got me thinking about what a quality book about shapes needs to consist of. Not only does the wording have to be accurate but the pictures do too.

- I know now what to look for in books and the rubric helps validate the information need to watch for. The rubric will also help me plan my lessons and help me carefully teach certain information.

Seven (5\%) PSTs extrapolated their knowledge about choosing representations for student learning beyond the specific context of this activity about shapes to specify that as teachers they would critique resources more broadly. Specifically, four (3\%) PSTs' responses were coded as Extrapolated Resources Shapes. In other words these PSTs focused on the same mathematical content as the activity, but extrapolated that to be an effective teacher they need to critique representations of shapes in resources beyond books. Moreover, three other PSTs (2\%) provided responses coded as PSTs' Extrapolated Resources Mathematics, because they extrapolated from the activity that they will now make sure to assess the accuracy of potential resources for any mathematical concept they teach.

- When it comes to teaching children about topics that seem so simple, this activity helped me realize books can sometimes not be beneficial. Many misconceptions were seen in these. When I have to teach them, I will make sure all my info is correct.

- It taught me to be very cautious about the resources I utilize. This experience taught me how introductory a topic can impact the understanding that is built upon it down the road.

Note that the last two responses included phrases such as "topics that seem so simple," which we interpreted as referring to topics broader than shapes; and "resources I utilize...how introductory a topic," which documented as meaning that PSTs transferred learning from the activity to a broader scope than just applicable to shape books. We were careful to use conservative coding. For example, revisit the six quotations we used to illustrate the Explicit Evidence of Books responses. The last three of those quotations explicitly mention shapes. In contrast, the first three PSTs might have meant that they would apply their new knowledge to the representations in books more broadly than for shape learning; however, because this was not explicit in their responses we used the more conservative code of Explicit Evidence of Shape-Related Books.

\section{PSTs' dispositions to teach at descriptive level}

Another theme found in response to the open questions about how the Shape Book Critique Activity changed how they will talk to children or plan instruction, involved ideas that could be interpreted in relation to the van Hiele framework (van Hiele, 1986), so we developed a coding scheme from PST responses to ensure each PST could be documented with a single code from the coding scheme in Appendix C. We documented only two PSTs (1.5\%) with the Visual Problematic code, meaning that they explicitly demonstrated they did not develop their Knowledge of Content and Students to overcome the early childhood myths (e.g., stated properties are too difficult or complicated for children) or provided responses that demonstrated their own Common Content Knowledge remained at the visual level (e.g., they stated an inaccurate idea about shapes based on visual prototypes). The responses of 16 PSTs (12\%) were coded as Visuals Matter, meaning that they stated the importance of using diverse visual exemplars. Half of the PSTs (50.4\%) had responses coded as Descriptive, such as: they explicitly indicated the activity helped them learn that properties determine shapes (reflecting Common Content Knowledge), or that teaching children about properties is important to effective instruction such as the response It is important to show children multiple examples and use properties, which we interpreted as growth in Knowledge of Content and Students as well as Knowledge of Content and Teaching. Another $25.6 \%$ of the PSTs provided ideas coded as Implicit Descriptive due to words like "technical terms" or being "specific," which we interpreted as indicating PSTs understood the importance of language and describing properties rather than relying on visuals without using the formal mathematical terms for such ideas. The four quotations that follow are representative responses with the key words bolded:

- Usually when looking at or describing shapes I don't care for details but this helped me learn details are important.

- I will be more descriptive as to what make a certain shape that shape, and show different kinds of examples.

- It makes you realize you need to be specific in the way you teach and talk about shapes...

- It shows you have to be careful with how you describe things and to be precise.

Another 14 PSTs (10.5\%) discussed the importance of providing learning experiences to help students develop understanding of relationships between classes (Relational Level). PST statements such as Show how often shapes could be "the same"--rectangle could be a square, illustrated an awareness of this informal deduction or relational level instruction.

\section{DISCUSSION}

Overall, this sample of 133 PSTs perceived that the Shape Book Critique Activity improved their knowledge relevant to teaching shapes, and their responses indicated what some of these new understandings were. We discuss the findings of the survey and content assessment in terms of the three intended goals shown in Table 1. This 40-minute activity facilitated PSTs to make progress toward the Common Content Knowledge-focused Goal 1, and accomplish Goals 2 and 3 focused on the Knowledge of Content and Students as well as Knowledge of Content and Teaching. 


\section{Goal 1}

A primary goal of the Shape Book Critique Activity was to improve an aspect of knowledge that Ball and colleagues (2008) labeled as Common Content Knowledge. Based on the preponderance of evidence about the Common Content Knowledge for geometric shapes of PSTs and in-service teachers (Fujita, 2012; Pickreign, 2007; Turnuklu et al., 2013; Van der Sandt \& Nieuwoudt, 2003), Goal 1 was phrased with the assumption that participating PSTs' Common Content Knowledge needed improvement: Recognize and improve own incomplete and/or inaccurate conceptions of geometric shapes. Note that the word "recognize" in Goal 1 reflected our intention that the activity would encourage PSTs to self-reflect about their Common Content Knowledge in addition to improving their actual knowledge. In spite of the short duration, the Shape Book Critique Activity facilitated more than half the PSTs to accomplish both parts of Goal 1. We interpreted this based on PST responses to the question: How if at all, did evaluating children's books with the given rubric improve your own knowledge about shapes? [This question is about your mathematics content knowledge, not how to teach it.] The more than half of PSTs who demonstrated that they became self-aware (53\%) chose words such as This activity made me value the knowledge teachers need to know about shapes in order to accurately teach children, which expressed a disposition for self-reflection that teachers need in order to be motivated to continuously learn more common content knowledge to teach their students effectively. PSTs' statements displayed in the results, such as Evaluating the children's books with the given rubric showed me that my knowledge is not what it should be, reflect this self-awareness of growth for Goal 1 . This PST's self-reflective statement also aptly summarizes the status of PST knowledge in general. According to standards in the United States (Common Core State Standards, 2010/2015), the Common Content Knowledge of shapes that this activity addressed with PSTs should have been mastered by about Grade 5, so it would be ideal in the future if Goal 1 of this activity with adults who will teach were to become unnecessary. Yet, at this time, fewer than one-tenth of the PSTs indicated this to be the case (just $9.8 \%$ disagreed that they learned Common Content Knowledge from the activity). To interpret how the activity influenced PSTs' Common Content Knowledge of geometric shapes warrants considering all PSTs except those who disagreed. Taken together then, the PSTs whose responses were coded as explicitly Agreed that the activity improved their shape knowledge, those who misunderstood the question to talk about future students rather than self-reflecting (Insufficient Evidence code), and those who had an inflated perception of their knowledge such that they claimed they needed no improvement yet explained at least one way the activity had improved their knowledge (Conflicting Evidence), the true impact on Common Content Knowledge would be in the range of $53 \%$ to $90.2 \%$ of the PSTs. Future survey designs might determine ways to ensure that PSTs self-reflect, such as Likert items that explicitly ask about the activity's impact on their own misconceptions.

The surveys documented PSTs' perceived changes, and the content test was able to assess current knowledge after completing the activity. As implemented, the activity was most effective at improving two aspects of Common Content Knowledge of geometric shapes: clarifying the distinctions between 2D and 3D shapes and a shift from partitive meanings of rectangles to a hierarchical meaning.

\section{Shape book critique clarified dimensionality}

Two ways of exploring the survey questions along with the content assessment triangulate that the Shape Book Critique Activity clarified for PSTs the distinction between 2D and 3D shapes. In the results, we documented typical quotations to support our claim that this theme was in PSTs' survey responses (e.g., It helped me to realize that real life items are not 2D shapes and that I can't just call a book a rectangle.). The PSTs frequent use of dimensionality in the open response survey questions that asked how the activity changed their thinking, as reflected by the prominence in the word cloud of the term "dimensional" (see Figure 1), this further substantiated that this change of dimensional understanding was a theme. The content test provided additional evidence we can interpret in relation to prior research. For instance, although Luneta (2014) found 63\% of PSTs conflated dimensionality of shapes, on our assessment just 15\% made this error. That few PSTs made this 2D/3D error after the activity, and that PSTs also reported it was the activity that changed this understanding, suggest that the Shape Book Critique Activity was useful in facilitating PSTs to overcome 2D and 3D conflation.

\section{Shape book critique fostered hierarchical conceptions of rectangles among more PSTs}

PSTs reported a change in their thinking that we can interpret using de Villiers' (1994) discussion of partitive and hierarchical classifications of quadrilaterals. Rectangles were just one of the shapes the PSTs considered as they evaluated a book and then discussed ideas as a whole class. Yet, the open response survey data revealed the theme that PSTs stated that the activity changed their thinking from conceptualizing rectangles in ways that fit a partitive definition to accepting a hierarchical classification system with statements such as: a rectangle isn't necessarily something with 2 sides long and 2 short because a square can be a rectangle too. Although due to the post-test only design the magnitude of improvement cannot be assessed, we can interpret the post-test data in relation to other research reports of rectangle accuracy. After this broad activity critiquing any shapes in children's books, $57 \%$ of PSTs correctly identified all rectangles including squares. This rectangle accuracy rate in the current study was greater than the $46 \%$ found by Ozdemir Erdogan and Dur (2014) and more than four times greater than the $13 \%$ accuracy Fujita and Jones (2007) reported. These prior studies were simply assessments of knowledge, so let us also consider the accuracy rate of our study in relation to Milsaps' (2013) study in which PSTs experienced an activity about quadrilaterals. After two lessons in which PSTs focused exclusively on quadrilaterals, Millsaps (2013) reported that $64 \%$ of the PSTs accurately identified rectangles. Whereas in the study reported here PSTs spent less than half the time and learned about quadrilaterals as well as other shapes, the post Shape Book Critique Activity accuracy rate was reasonably close to Millsaps' findings (2013; differing by just 7\%). Although the rectangle accuracy rate of $57 \%$ in our study is insufficient knowledge if this were the rate at the time teachers begin teaching, in both the methods and content courses the Shape Book Critique was the introductory activity of a geometry unit with subsequent activities to further clarify misconceptions. Nevertheless, to increase the power of the Shape Book Critique as the introductory activity to a geometry unit, we have since changed the activity and rubric to better foster PSTs to change from a partitive understanding of 
rectangles to a hierarchical understanding as standards for teaching knowledge require (AMTE, 2017). These changes will be discussed along with other changes to the activity in the Conclusions section.

\section{Goal 2}

PSTs demonstrated in the survey responses that they overcame early childhood myths or conceptions that "simple shapes" are enough (Lee \& Ginsburg, 2009) and began to understand what their future students are likely to think about shapes due to informal learning experiences. This reflects growth in relation to Goal 2: Recognize and anticipate student conceptions of shapes; understand what students are capable of and need in order to learn geometric shapes. Almost all PSTs explained that this activity changed how they understand students' thinking such that they would talk with children differently about shapes (97.7\%). A majority of PSTs also indicated the activity helped them understand the conceptions of shapes with which children were likely to come to their classrooms (83.5\%). This rate of affirmative responses indicated that the majority of PSTs valued this activity as worthwhile for developing their Knowledge of Content and Students, yet even this rate may under-reflect the true value due to the flaw of the survey question as discussed in the results. That is, every PST who answered the part of the question focused on Knowledge of Content and Students, valued the activity as worthwhile by indicating something they learned about student knowledge of shapes (Recall in Table 2 that none of the PSTs disagreed about the value of the activity for this purpose.). The rate of Inconclusive Evidence codes seemed to be due to the nature of the question as a two-part question (i.e., What did evaluating children's books with the given rubric help you learn about children's shape learning and how you would plan learning experiences in the future?), such that $16.5 \%$ of PSTs omitted answering the first part related to Goal 2 and answered just the second part of the question intended to gather evidence for Goal 3. Moreover, we believe that a review of the qualitative evidence reported in the results substantiates the claim that the activity facilitated growth toward Goal 2, and we restate an example here to reiterate the ways in which PSTs talked about their new Knowledge of Content and Students: Shape learning is going to be a difficult topic to teach with so many inaccurate books the kids will be exposed to. This statement and the others in the results section are typical indications from the data that showed this short activity provided important insights that PSTs gleaned about how their future students will likely think about shapes even before entering their classrooms.

\section{Goal 3}

Almost all PSTs said the activity changed how they will plan instruction (92.5\%) about shapes, which reflects growth of what Ball and colleagues (2008) defined as Knowledge of Content and Teaching. One important part of this knowledge is knowing how to select representations of shapes for effective instruction (Ball et al., 2008). Two themes of selection criteria were found in the PSTs' survey responses that demonstrated growth in Knowledge of Content and Teaching about selecting representations: (a) varied visual examples along with properties of shapes are required, and (b) if books are used as sources of representations these need to be critically assessed.

Given that the survey questions asked PSTs to explain how the activity changed their thinking, $98.5 \%$ of the PSTs reported learning from this activity that varied visual representations and/or also properties are crucial to the teaching of shapes, with just 1.5\% (Visual Problematic code) maintaining their adherence to early childhood myths described by Lee and Ginsburg (2009). This means the evidence shows the Shape Book Critique Activity facilitated almost every PST, as part of their growing Knowledge of Content and Students, to overcome what Lee and Ginsburg (2009) would describe as the outdated belief that prototypical simple shapes are the way to begin instruction with young children. Once we attend to only those responses coded at the Implicit Descriptive, Descriptive, or Relational levels, although they were not specifically asked about the use of properties for instruction, this short activity influenced $76 \%$ of PSTs to report they changed from a disposition of instructional approaches focused on visual naming to ensure their future students attend to details and properties of shapes. Statements reported in the results such as, It is important to show children multiple examples and use properties, conveyed this idea in PSTs' own words.

Moreover, recall language in responses that emphasized how using the rubric shifted their thinking from visuals (i.e., you need more than just examples) to defining properties (i.e., what makes a shape) with statements such as, It taught me that you need more than just examples of shapes, but you also need to know what makes a shape, the shape it is. Thus, this short activity aided at least three-fourths of the PSTs to shift from a disposition we can interpret with van Hiele framework (van Hiele, 1986) from visual level instruction to at least descriptive level reasoning for their future teaching practice. This transformation that the PSTs indicated reflects changes in how they will select representations for instruction, which means the activity facilitated these PSTs' growth in what Ball and colleagues (2008) defined as Knowledge of Content and Teaching.

Recall Goal 3 was Learn how to critically evaluate shape-related resources, such as children's books and develop the disposition to do so prior to use. Almost all students reported this activity provided new insights about how to choose the representations of children's books and representations for shape instruction in general, which reflects achievement of Goal 3 and improvement in PSTs' Knowledge of Content and Teaching. Quotations reported in the findings (e.g., I never thought about critiquing books before this activity. I always thought they were reliable because they were published.) provided evidence that the Shape Book Critique Activity incited them to see shape books in new ways and overcome prior assumptions about the validity of the mathematics in published books, so they now have the disposition to look at other books carefully. Although the survey questions did not ask PSTs if it changed how they will use books, rather the survey asked at a broad level how this activity changed how they will plan, a majority of PSTs (59\%) specified the disposition that they will carefully select books and other resources they will use with students and also that the activity aided them to begin to learn how to effectively evaluate such resources (e.g., I know now what to look for in books and the rubric helps validate the information need to watch for.) Moreover, some PSTs framed this in terms of a disposition to help their students understand information literacies (The Association of College \& Research Libraries, 2016) more broadly, evident when they stated ideas such as: Not everything you read in a book is right. I would show that to my class. For this first study of the efficacy of the shape book critique activity across content and methods courses, the survey questions were stated 
generally so that we could interpret what the PSTs found salient about their experience with the activity. Future survey questions could use these data to specify questions about the same themes many PSTs expressed in the open response items such that future data could be collected from each PST about the common themes. For example, a question could be added to specifically ask: "How if at all, did evaluating the shape book with the given rubric change how you think about children's books when you are a teacher?" To understand how the activity influenced their growth in Knowledge of Content and Teaching beyond children's books, a separate question could be asked about how the activity changed how they would plan instruction of shapes when not using children's books.

\section{Summary}

The implementation varied due to course type (methods and content course), variations in how each instructor implemented the activity (see Appendix B), and the fact that the method instructor had extensive experience using the rubric with PSTs and inservice teachers whereas it was the content instructor's first implementation. In spite of these variations, there were no significant differences in outcomes between course types for all three activity goals: improving Common Content Knowledge, Knowledge of Content and Students, and Knowledge of Content and Teaching. This suggests that the rubric itself and other broad principles of implementing the activity might make this scalable across varied contexts of teacher education programs. Additional research should continue in both course types as well as longitudinally across PSTs' programs.

\section{CONCLUSION}

Flevares and Schiff called for "teacher professional development that incorporates practicing strategies for critically evaluating geometry-based literature" (2014, p. 459). This call for teachers to learn how to critically evaluate representations of mathematics such as children's literature can be interpreted as the need for activities to improve PSTs' Knowledge of Content and Teaching for geometry (Ball et al., 2008). The Shape Book Critique Activity specified here provided a short 40-minute professional development experience that addressed this call. Moreover, the primary purpose of this activity was to use this approach to provide PSTs the opportunity to simultaneously improve two other aspects of Mathematical Knowledge for Teaching: Common Content Knowledge and Knowledge of Content and Students. This paper shared the efficacy of this novel approach of evaluating children's shape-related books using a rubric designed to draw teacher attention to and clarify information about 2D shapes as a way to improve three aspects of PSTs' Mathematical Knowledge for Teaching. This Shape Book Critique activity is a promising learning experience for PSTs in methods as well as mathematics content courses.

A challenge for mathematics teacher educators' efforts to improve PSTs' mathematical knowledge for teaching is to provide activities that the PSTs perceive as relevant to their future teaching practice and that also support meaningful learning for the PSTs in the present. Each of the survey questions prompted PSTs to reflect on how the activity transformed their Mathematical Knowledge for Teaching (Ball et al., 2008) in some way with the transformative verbs in the question prompts being: "improve" (Q1), "change" (Q2), and "learn" (Q3). We were surprised by the extent to which PSTs valued this instructional activity. The fact that almost all of the 133 participating PSTs, at two different stages of their program, indicated the activity changed how they will talk to children about shapes (98\%) and their future planning of instruction (93\%) suggests strong "buy-in" by PSTs. The documented PSTs' typical survey responses and descriptive statistics in the results along with the prominence of their words displayed in the word cloud (see Figure 1), we believe supported and contextualized our interpretation of this "buy-in" or perceived relevancy using PSTs' own words. From the 35 quotations in the results section that reported PSTs' typical perceptions of the impact of the Shape Book Critique Activity, we conclude by restating one typical quotation for each aspect of the Mathematical Knowledge for Teaching that the activity was designed to address:

- Common Content Knowledge: This activity made me value the knowledge teachers need to know about shapes in order to accurately teach children.

- Knowledge of Content and Students: Children's shape learning is way more complex than what I first thought \& it is very important to not be misleading.

- Knowledge of Content and Teaching: I know now what to look for in books and the rubric helps validate the information need to watch for. The rubric will also help me plan my lessons and help me carefully teach certain information.

The fact that PSTs themselves appreciated the value of the activity for improving their Mathematical Knowledge for Teaching, especially given prior research on math anxiety among elementary teachers (i.e., Novak \& Tassell, 2017; Rech et al., 1993), motivates us to continue using and refining it to develop PSTs' Mathematical Knowledge for Teaching geometric shapes.

\section{Improvements for Ongoing and Future Implementations of Shape Book Critique Activity}

Two changes were made to the instructional activity due to specific comments in the open response survey questions. As mentioned in the results, at least two PSTs shared that they did not learn as much from the activity as they thought the rubric offered, because the book they analyzed was only about one shape or a shape they already knew well and thus limited what they could learn. Consequently, we now implement the activity with the direction to choose children's books that have at least three different shapes (See Appendix D How to Implement Shape Book Critique Activity). Moreover, the names of shapes should be in the text of the book, so that it is clear the author intends to teach geometric shapes, because this provides the PSTs and in-service teachers the opportunity to more fully use the rubric criteria to learn how to assess the visuals and words of shape-related books, thus providing more opportunities to improve their Common Content Knowledge. 
With each revision of the rubric over the ten years prior to this data collection, the first author restricted the rubric to one page front and back, because busy teachers typically request a short resource that distills key elements of effective instruction. Based on the analyses reported here and subsequent focus groups with in-service teachers and PSTs, however, the rubric was lengthened and reframed as a rating scale. This was done because the teachers themselves said that although it would lengthen the document, they needed embedded in the rating scale the explicit criteria to help them understand the mathematics and also an explanation of why the criteria matter for students. The results reported here informed these discussions with in-service teachers and PSTs to determine which aspects required explanation and examples on the revised document. For example, due to teachers' difficulties overcoming the partitive definition of a rectangle to accept a hierarchical conception of a rectangle (Fujita, 2012; Pickreign, 2007; Turnuklu et al., 2013), the portion of the rubric used in this study (see Appendix A) that said to proceed with caution if a book "states that a rectangle must have two sides longer than the others," was changed in the new rating scale where Nurnberger-Haag (2018) added an explanation using the prefix and root word of "rect-angle" as meaning right-angled to this rubric criterion. In other words, Common Content Knowledge statements were explicitly added to the new version, whereas the explanation in the version used in the current study focused on evaluating the representations for children's use (Knowledge of Content and Teaching). Innumerable other such changes were made, primarily due to subsequent focus groups that occurred outside the scope of this study (see Nurnberger-Haag, 2018). The resulting published version we are using in practice as well as in ongoing studies-framed as the Traffic Light Rating Scale for shape-related books-was published as open source in order to facilitate this scale to be widely used (Nurnberger-Haag, 2018, Open source access https://library.osu.edu/ojs/index.php/OJSM/article/view/6041).

\section{Broaden the Scope of Stakeholders Who Learn from the Shape Book Critique Activity}

The minimal allotment of time required to do the Shape Book Critique Activity might make this especially attractive for mathematics teacher educators to consider implementing in a variety of courses and contexts with the diverse range of stakeholders who impact children's learning of geometric shapes. Thus, in Appendix D we specified our current recommendations for How to Implement the Shape-Book Critique Activity to support mathematics educators across many contexts, grade-bands, and languages to explore in practice and through research the potential of using the Traffic Light Rating Scale (Nurnberger-Haag, 2018) to evaluate shape books in order to improve teachers' mathematical knowledge for teaching.

All of the students in the methods course had already completed the content course so they should have had higher Common Content Knowledge than the content course participants; however, no significant differences in Common Content Knowledge were found between PSTs in a content course versus the methods course after their only experience critiquing shape books. Thus, we believe continued use of this instructional activity in mathematics content courses for PSTs where the focus is usually on the development of Common Content Knowledge is warranted, as well as in methods courses where the other aspects of Mathematical Knowledge of Teaching are the primary foci.

Although this study reported data of PSTs who were primarily in early childhood and special education licensure programs, prior research on secondary teachers' common content knowledge of geometric shapes has been shown to be similar to that of elementary teachers (Halat, 2008a). Consequently, we suggest it would be prudent to research how, if at all, secondary PSTs' Common Content Knowledge, Knowledge of Content and Students, or Knowledge of Content and Teaching might also benefit from this Shape Book Critique Activity.

Moreover, we believe it is important to broaden the scope of stakeholders who experience such activities beyond teachers. For instance, the Shape Book Critique Activity is currently being used to collaborate with librarians to guide collection and circulation decisions as well as to create better collaborative efforts between academic librarians and mathematics teacher educators at institutions that prepare future librarians and teachers (e.g., Nurnberger-Haag et al., 2019). In practice the Shape Book Critique Activity has also been used with a mixed group of teachers and parents on a school's curriculum committee and with parents in a parent education night, such that it could be worthwhile to conduct studies to determine in what, if any, ways the activity should be modified to help families improve geometric common content knowledge to support their children's developing knowledge and see their children's shape books in a new way. As discussed in Nurnberger-Haag (2017, 2018), the creators of children's books must also become part of the solution. These books are created with the intent to teach, so although authors and publishers are not teachers, in order to create productive learning resources the authors and publishers must themselves have accurate Common Content Knowledge. Moreover, given that these authors and publishers create and select representations from which children will learn (i.e., Knowledge of Content and Teaching), ideally before creating such resources for shapes they would develop this knowledge through the criteria in Nurnberger-Haag (2018) in order to select representations that will support and not interfere with children's learning. Research could investigate in what ways the Shape Book Critique Activity could be used to improve various aspects of the mathematical knowledge as relevant to the nuances of these varied stakeholders: shape book users such as librarians and parents/guardians versus shape book creators such as authors and publishers.

Furthermore, PSTs' and in-service teachers' Mathematical Knowledge for Teaching of shapes has been documented as a global problem of practice. Considering only articles published in English, such documentation includes research from Israel (Tsamir et al., 2015), Poland (Pytlak \& Swoboda, 2017); Romania (Marchis, 2012), Scotland (Fujita \& Jones, 2007), South Africa (Luneta, 2014), Turkey (Halat, 2008a, 2008b; Ozdemir Erdogan \& Dur, 2014; Turnuklu et al., 2013), the United Kingdom (Fujita, 2012), and the United States (Lee \& Ginsburg, 2009; Pickreign, 2007). Collaborative studies and translations of the rating scale into languages other than English are currently being conducted to broaden access to this professional development activity. We hope that mathematics teacher educators across countries will join in collaborations to translate and use the rating scale and description of the activity in Appendix D to broaden the scope of international access and investigation of the Shape Book Critique Activity. 
Author contributions: All authors have sufficiently contributed to the study, and agreed with the results and conclusions.

Funding: No funding source is reported for this study.

Declaration of interest: No conflict of interest is declared by authors.

\section{REFERENCES}

The Association of College and Research Libraries. (2016). Framework for information literacy for higher education. http://www.ala.org/acrl/sites/ala.org.acrl/files/content/issues/infolit/framework1.pdf

Association of Mathematics Teacher Educators. (2017). Standards for Preparing Teachers of Mathematics. https://amte.net/standards

Ball, D. L., Thames, M. H., \& Phelps, G. (2008). Content knowledge for teaching: What makes it special. Journal of Teacher Education, 59(5), 389-407. https://doi.org/10.1177/0022487108324554

Battista, M. T., \& Clements, D. H. (1991). LOGO Geometry. Silver Burdett Company.

Burger, W., \& Shaughnessy, J. (1986). Characterizing the van Hiele levels of development in geometry. Journal for Research in Mathematics Education, 17(1), 31-48. https://doi.org/10.2307/749317

Clements, D. H., \& Battista, M. T. (1991). LOGO Geometry. Silver Burdett Ginn.

Clements, D. H., Swaminathan, S., Hannibal, M. A. Z., \& Sarama, J. (1999). Young children's concepts of shape. Journal for Research in Mathematics Education, 30, 192-212. https://doi.org/10.2307/749610

Cockcroft, W. H., \& Marshall, J. (1999). Educating Hannah: It's a what? Teaching Children Mathematics, 5(6), 326-330. https://doi.org/10.5951/tcm.5.6.0326

Common Core State Standards. (2010, 2015). Common Core Standards. Initiative. http://www.corestandards.org/

DePaolo, C. A., \& Wilkinson, K. (2014). Get your head into the clouds: Using word clouds for analyzing qualitative assessment data. TechTrends, 58(3), 38-44. https://doi.org/10.1007/s11528-014-0750-9

de Villiers, M. (1994). The role and function of a hierarchical classification of quadrilaterals. For the Learning of Mathematics, 14(1), 11-18. https://flm-journal.org/Articles/58360C6934555B2AC78983AE5FE21.pdf

Flevares, L. M., \& Schiff, J. R. (2014). Learning mathematics in two dimensions: A review and look ahead at teaching and learning early childhood mathematics with children's literature. Frontiers in Psychology, 5, 1-12. https://doi.org/10.3389/fpsyg.2014.00459

Fujita, T., \& Jones, K. (2007). Learners' understanding of the definitions and hierarchical classification of quadrilaterals: Towards a theoretical framing. Research in Mathematics Education, 9(1), 3-20. https://doi.org/10.1080/14794800008520167

Fujita, T. (2012). Learners' level of understanding of the inclusion relations of quadrilaterals and prototype phenomenon. The Journal of Mathematical Behavior, 31(1), 60-72. https://doi.org/10.1016/j.jmathb.2011.08.003

Fuys, D., Geddes, D., \& Tischler, R. (1988). The van Hiele model of thinking in geometry among adolescents. Journal for Research in Mathematics Education Monograph, 3. https://doi.org/10.2307/749957

Halat, E. (2008a). Pre-service elementary school and secondary mathematics teachers' van Hiele levels and gender differences. Issues in the Undergraduate Mathematics Preparation of School Teachers, 1. http://www.k12prep.math.ttu.edu/journal/1.contentknowledge/halat01/article.pdf

Halat, E. (2008b). In-service middle and high school mathematics teachers: Geometric reasoning stages and gender. The Mathematics Educator, 18(1), 8-14. https://files.eric.ed.gov/fulltext/EJ841566.pdf

Harper, N. W., \& Daane, C. J. (1998). Causes and reduction of math anxiety in preservice elementary teachers. Action in Teacher Education, 19(4), 29-38. https://doi.org/10.1080/01626620.1998.10462889

Hill, H. C., Ball, D. L., \& Schilling, S. G. (2008). Unpacking pedagogical content knowledge: Conceptualizing and measuring teachers' topic-specific knowledge of students. Journal for Research in Mathematics Education, 39, $372-400$. https://pubs.nctm.org/view/journals/jrme/39/4/article-p372.xml

Kutluca, T. (2013) The effect of geometry instruction with dynamic geometric software; GeoGebra on Van Hiele geometry understanding levels of students. Educational Research and Reviews, 8(17), 1509-1518. https://doi.org/10.5897/ERR2013.1554

Landis, J. R., \& Koch, G. G. (1977). The measurement of observer agreement for categorical data. Biometrics, 33(1), $159-174$. https://doi.org/10.2307/2529310

Lee, J. S., \& Ginsburg, H. P. (2009). Early childhood teachers' misconceptions about mathematics education for young children in the United States. Australasian Journal of Early Childhood, 34(4), 37-45. https://doi.org/10.1177/183693910903400406

Luneta, K. (2014). Foundation phase teachers' (limited) knowledge of geometry. South African Journal of Childhood Education, 4(3), 71-86. https://doi.org/10.4102/sajce.v4i3.228

Marchis, I. (2012). Preservice primary school teachers' elementary geometry knowledge. Acta Didactica Napocensia, 5(2), 33-40. http://adn.teaching.ro/

Millsaps, G. (2013). Challenging preservice elementary teachers' image of rectangles. Mathematics Teacher Educator, 2(1), $27-41$. https://doi.org/10.5951/mathteaceduc.2.1.0027 
Nesmith, S., \& Cooper, S. (2010). Trade books in the mathematics classroom: The impact of many, varied perspectives on determinations of quality. Journal of Research in Childhood Education, 24(4), $279-297$. https://doi.org/10.1080/02568543.2010.510086

Novak, E., \& Tassell, J.L. (2017). Studying preservice teacher math anxiety and mathematics performance in geometry, word, and non-word problem solving. Learning and Individual Differences, 54, 20-29. https://doi.org/10.1016/j.lindif.2017.01.005

Nurnberger-Haag, J. (2017). A cautionary tale: How children's books (Mis)teach shapes. Early Education and Development, 28(4), 415-440. https://doi.org/10.1080/10409289.2016.1242993

Nurnberger-Haag, J. (2018). Follow the signs to promote accurate geometric shape knowledge: Together We can break the cycle of misinformation. Ohio Journal of School Mathematics, 80. https://ibrary.osu.edu/ojs/index.php/OJSM/article/view/6041

Nurnberger-Haag, J., Alexander, A. N., \& Powell, S. R. (2021). What counts in number books? A content-domain specific typology to evaluate children's books for mathematics. Mathematical Thinking and Learning, 23(2), 145-169. https://doi.org/10.1080/10986065.2020.1777365

Nurnberger-Haag, J., Holford, T.L, Bryk, K.M., Strozyk, H., Harder, M., \& Davidsaver, K (2019). A ball is not a circle: How to spot mathematical inaccuracies to improve and use shape book collections. Teacher Librarian, 1(47), 8-13.

Ozdemir Erdogan, E., \& Dur, Z. (2014). Preservice mathematics teachers' personal figural concepts and classifications about quadrilaterals. Australian Journal of Teacher Education, 39(6), 8. https://doi.org/10.14221/ajte.2014v39n6.1

Pickreign, J. (2007). Rectangles and rhombi: How well do preservice teachers know them? Issues in the Undergraduate Mathematics Preparation of School Teachers, 1. http://www.k-12prep.math.ttu.edu/journal/1.contentknowledge/pickreign01/article.pdf

Pytlak, M., \& Swoboda, E. (2017). The impact of the prototypical images on the formal understanding of geometric concepts. Didactica Mathematicae, 39, 71-100.

Riazi, A. M. (2016). The Routledge encyclopedia of research methods in applied linguistics. New York: Routledge.

Rech, J., Hartzell, J., \& Stephens, L. (1993). Comparisons of mathematical competencies and attitudes of elementary education majors with established norms of a general college population. School Science and Mathematics, 93(3), $141-144$. https://doi.org/10.11 11/ j.1949-8594. 1993.tb1221 2.x

Roberts, S. K. (2007). Watch what you say. Teaching Children Mathematics, 14(5), $296-301$. https://www.nctm.org/Publications/teaching-children-mathematics/2007/Vol14/Issue5/Watch-What-You-Say/

Schifter, D. (1999). Learning geometry: Some insights drawn from teacher writing. Teaching Children Mathematics, 5(6), 360-367. https://pubs.nctm.org/view/journals/tcm/5/6/article-p360.xml

Sunzuma, G., \& Maharaj, A. (2019). In-service teachers' geometry content knowledge: Implications for how geometry is taught in teacher training institutions. International Electronic Journal of Mathematics Education, $14.633-646$. https://doi.org/10.29333/iejme/5776

Tsamir, P., Tirosh, D., Levenson, E., Barkai, R., \& Tabach, M. (2015). Early-years teachers' concept images and concept definitions: Triangles, circles, and cylinders. ZDM, 47(3), 497-509. https://doi.org/10.1007/s11858-014-0641-8

Turnuklu, E., Gundogdu Alayli, F., \& Akkas, E. N. (2013). Investigation of prospective primary mathematics teachers' perceptions and images for quadrilaterals. Educational Sciences: Theory and Practice, 13(2), $1225-1232$. https://files.eric.ed.gov/fulltext/EJ1017328.pdf

van der Sandt, S., \& Nieuwoudt, H. D. (2003). Grade 7 teachers' and prospective teachers' content knowledge of geometry. South African Journal of Education, 23(3), 199-205. https://www.ajol.info/index.php/saje/article/view/24934

van Hiele, P. M. (1986). Structure and insight: A theory of mathematics education. Orlando, FL: Academic Press.

van Hiele, P. M. (1999). Developing geometric thinking through activities that begin with play. Teaching Children Mathematics, 5(6), 310-316. https://www.nctm.org/Publications/Teaching-Children-Mathematics/1999/Vol5/Issue6/Developing-GeometricThinking-through-Activities-That-Begin-with-Play/

Yilmaz Genc, M. M., Akinci Cosgun, A., \& Pala, S. (2017). A study of mathematical content provided in illustrated children's books. Eurasian Journal of Educational Research, 69, 159-175. https://doi.org/10.14689/ejer.2017.69.9 


\section{APPENDIX A: Rubric Used During This Shape-Book Critique Activity}

\section{Checklist for Choosing a Book about Shapes}

\section{Caution! These Characteristics Likely Hinder Concept Development}

"Label" here means that the book equates the object with the named shape. If a book asks children to trace circles or find footprints of three-dimensional objects that are the two-dimensional shape, then these books might help concept development. This is rare. Most often books show images with only shape names.

If a book does any of the following, proceed with caution:

$\square$ Shows only one image for any shape named.

$\square$ States that a rectangle must have two sides longer than the other two sides.

$\square$ Labels a circle, but shows a sphere such as a ball or piece of fruit.

$\square$ Shows a cylinder such as a coin or a can and labels it a circle.

$\square$ Labels a triangle, but shows something like a hat, pie or pizza wedge, musical triangle, or a coat hanger

$\square$ Shows and labels a square, but then uses the term diamond for a square rotated 45 degrees.

$\square$ Images of triangles are only equilateral or acute-isosceles

$\square$ Explains that the parallelograms and rhombi are slanted (can't have right angles).

\section{Potential to Help Support General Concept Development of Shapes}

Put a plus mark through each of the following. The more of the following plus marks a book collects, the more likely it is that the book could facilitate development of accurate geometric concepts (but there could still be problems):

$\square$ Does the book use the descriptive van Hiele level by talking about accurate properties of shapes, rather than just labeling images with shape names?

$\square$ Are children asked to trace the shapes they find with their finger or does the book state that the footprint of a 3-D object is a 2-D shape, rather than the entire 3-D object?

$\square$ Are a majority of the images of shapes shown in an orientation other than horizontal?

$\square$ Are any non-examples provided?

\section{More power! Books that do more of the following are potentially powerful tools for helping to develop concepts of specific shapes!}

Put a plus mark through each of the following. The more of the following plus marks a book collects, the more likely the book is to facilitate development of accurate concepts of specific shapes (but there could still be problems):

Turn to the rectangle page or pages:

$\square$ Are images of squares included with the term rectangle (the word square is not necessary, just the picture of a square)?

$\square$ Are a majority of the images of squares or rectangles shown in an orientation other than horizontal?

$\square$ Are any nonexamples provided?

$\square$ Are any accurate properties described? Which ones?

Turn to the triangle page or pages:

$\square$ Are there scalene triangles?

$\square$ Are there obtuse triangles?

$\square$ Are a majority of the images of triangles shown in a position other than horizontal?

$\square$ Are any nonexamples provided?

$\square$ Are any accurate properties described? Which ones?

Turn to the parallelogram, rhombus, or trapezoid pages:

$\square$ Are pictures of squares, other rectangles, and rhombi labeled as parallelograms?

$\square$ Are pictures of squares labeled as rhombi (a rhombus)?

$\square$ Are the majority of the trapezoids NOT isosceles?

$\square$ Are any nonexamples provided?

$\square$ Are any accurate properties described? Which ones?

Turn to any pages that show polygons by name using the number of sides or angles (e.g., quadrilateral, pentagon, hexagon, etc.)

$\square$ Are there concave examples of the polygons?

$\square$ Are there irregular examples of the polygons?

$\square$ Are any accurate properties described? Which ones? 


\section{APPENDIX B: Comparison of How the Two Instructors Implemented the Shape-Book Activity in Their Respective Course Type}

\begin{tabular}{|c|c|c|}
\hline Aspect & Content Course & Methods Course \\
\hline Course Affiliation & Mathematics department & Education department \\
\hline \multirow{7}{*}{$\begin{array}{l}\text { Readings Assigned and Geometry } \\
\text { Instruction Prior to Activity }\end{array}$} & Prior to activity course session: & Course session prior to activity: \\
\hline & - Roberts (2007) & - Roberts (2007) \\
\hline & - Cockcroft \& Marshall (1999) & Prior to activity course session: \\
\hline & Prior to activity during session: & - Cockcroft \& Marshall (1999) \\
\hline & - Mini-lecture on van Hiele levels & • van Hiele (1999) \\
\hline & & Prior to activity during session: \\
\hline & & $\begin{array}{l}\text { - Briefly discussed van Hiele levels emphasizing } \\
\text { visual and descriptive distinction }\end{array}$ \\
\hline Children's Books Used & $\begin{array}{l}\text { The instructor primarily brought books for PSTs to } \\
\text { use (mostly acquired from local library) }\end{array}$ & $\begin{array}{l}\text { Each PST required to bring a shape-related book } \\
\text { from their field placement, library, or other source. } \\
\text { Instructor brought in a few books to supplement } \\
\text { whole class discussion (in case certain ideas were } \\
\text { not found in books PSTs brought). }\end{array}$ \\
\hline PST Groupings & $\begin{array}{l}\text { Mainly groups of } 4 \text { (due to number of books } \\
\text { available) }\end{array}$ & Pairs and a few trios \\
\hline \multirow[t]{5}{*}{ Instructor Prompt to Begin Activity } & $\begin{array}{l}\text { As you analyze the children's shape book, consider } \\
\text { these questions: }\end{array}$ & $\begin{array}{l}\text { If these books were children's only experiences with } \\
\text { shapes what would they "know" and "think"? }\end{array}$ \\
\hline & $\begin{array}{l}\text { 1. If this were a first experience with shapes (such } \\
\text { as a young child would have), what would be the } \\
\text { "take-away" knowledge about shapes? In other } \\
\text { words, what would the child "know" or "think"? }\end{array}$ & \\
\hline & $\begin{array}{l}\text { 2. Are there any misconceptions or problems with } \\
\text { the way the book portrays shapes? }\end{array}$ & \\
\hline & $\begin{array}{l}\text { 3. What are the potential benefits of reading this } \\
\text { book? }\end{array}$ & \\
\hline & $\begin{array}{l}\text { 4. What van Hiele levels were used or evident in the } \\
\text { book? }\end{array}$ & \\
\hline \multirow[t]{2}{*}{ Approximate Time Spent } & 20 minutes small group & 20 minutes small group \\
\hline & 20 minutes whole class & 20 minutes whole class \\
\hline
\end{tabular}




\section{APPENDIX C: Survey Question Coding Schemes}

\section{PSTs' Perceptions as to Whether Analyzing Books with the Rubric Improved Their Content Knowledge}

Agree Explicit: Explicitly stated in some way the activity improved their own content knowledge or expressed that they learned something either (think of this code as did they learn more content?)

- at the broad level of how well they knew their shapes or correcting own misconceptions or some specific idea that they explicitly stated they learned through this or

- explicitly provided an idea they had that was wrong before (even if didn't say this activity "fixed" it) for example, I was taught that a square wasn't a rectangle in response to Q1 wording would count as agreeing that this activity changed that original knowledge

Agree Refreshed: Stated or implied a "review" or "refresh" of content knowledge they may have forgotten. This code reflects that they will remember more content when teaching students because of this activity, but does not acknowledge that they previously had any misconceptions.

Insufficient Evidence: Generally this code is used because the participant focused on student learning and how they would teach rather than reflecting on their own content knowledge.

Conflicting Evidence: A respondent may explicitly disagree that the activity helped their own knowledge, yet a change they identified reveals that they may just not have been aware that they actually had some inaccurate knowledge [e.g., "I already knew my shapes, so this didn't help me. However, I won't call a pyramid a triangle with children, for example."]

Disagree Explicit: Explicitly stated in some way that the activity didn't help their own knowledge. This may include that they already knew the information or because the book they used had too few shapes, and so forth. Answers of not applicable or N/A would also count as this code.

\section{PSTs' Perceptions as to Whether Analyzing Books Changed How They Would Talk with Children}

Agree Explicit: Explicitly stated in some way the activity changed how they will talk with children about shapes or expressed something they would do in the future or identified a need for how to talk with children about shapes.

Agree Refreshed: A respondent may say they used to know how to talk with children about shapes and the activity reminded them.

Insufficient Evidence: Generally this code is used because it is unclear if the activity changed how they will talk with children about shapes.

Conflicting Evidence: A respondent may explicitly disagree that the activity changed how they will talk with children about shape, yet expressed something they would do in the future or identified a need for how to talk with children about shapes.

Disagree Explicit: Explicitly stated in some way that the activity didn't change how they will talk with children about shape.

Code each response for the codes above. Enter confidence rating of 3 (completely confident), 2 (mostly confident), 1 (warrants discussion).

\section{PSTs' Perceptions as to Whether Analyzing Books with the Rubric Improved Their Knowledge about What Children Know} or How Children Learn about Shapes

Agree Explicit: Explicitly stated in some way the activity changed what they know about children's shape knowledge or how children learn or expressed some idea children know (implied due to the activity)

Agree Refreshed: A respondent may say they used to know what children understand or how children learn and the activity reminded them.

Insufficient Evidence: Generally this code is used because it is unclear if the activity changed what they know about children's shape knowledge or how children learn shapes.

Conflicting Evidence: A respondent may explicitly disagree that the activity changed their knowledge about children's shape knowledge, yet expressed something about what children know or need in order to learn that seemed to be in response to the activity.

Disagree Explicit: Explicitly stated in some way that the activity didn't change how what they know about children's shape knowledge or how children learn shapes.

PSTs' Perceptions as to Whether Analyzing Books with the Rubric Changed How They Would Plan Learning Experiences in the Future

Agree Explicit: Explicitly stated in some way the activity changed how they will plan learning experiences about shapes or expressed something they would do in the future or identified a need for how to talk with children about shapes.

Agree Refreshed: A respondent may say they used to know how to plan learning experiences and the activity reminded them.

Insufficient Evidence: Generally this code is used because it is unclear if the activity changed how they will plan learning experiences about shapes.

Conflicting Evidence: A respondent may explicitly disagree that the activity changed how they will plan learning experiences about shapes, yet expressed something they would do in the future or identified a need for how to talk with children about shapes. 
Disagree Explicit: Explicitly stated in some way that the activity didn't change how they will plan learning experiences about shapes.

\section{Properties Are Important and Other van Hiele Level Evidence}

Responses included a theme of properties and specifics, which led us to code related to van Hiele levels even though the survey questions were left open-ended to see what they reported learning. When codes listed as a or b below these are just criteria that can satisfy the code, these letters do not constitute separate codes.

Relational Level (Visual Variations with Properties of shape important for learning category relationships):

a) PST states that s/he will provide or importance of teaching the properties of shapes to promote understanding of category relationships (e.g., squares are rectangles) AND varied visuals (varied orientations and/or varied types of a shape and/or non-examples compared to examples) or

b) States that teaching properties of shape (may use words such as "property" "describe" "description" "descriptive" "parts" "specific aspects" "attributes" and similar ideas; note "specifics" may not imply specific properties, carefully reread the response to determine if intent can be determined as specific name making it implicit descriptive below) are critical generally for shape identification and determining how shapes relate to each other (e.g., squares are rectangles) or

c) Any of the above about own MCK (but in reference of property).

Descriptive (Visual Variations with Properties of shape important for learning):

a) PST states that $s /$ he will provide or importance of teaching the properties of shapes AND varied visuals (varied orientations and/or varied types of a shape and/or non-examples compared to examples); or

b) States that teaching properties of shape are critical generally for shape identification (may use words such as "property," "describe," "description," "descriptive," "parts," "specific aspects," "attributes" and similar ideas; note "specifics" may not imply specific properties, carefully reread the response to determine if intent can be determined as specific name making it implicit descriptive below), or

c) At least one specific property stated that they will be sure to teach.

Implicit Descriptive: (Indication the PST understands the importance of properties for shape definitions and/or mathematical precision)

PST refers to importance of using "technical terms" or being specific, or correct names of shapes with students, which would mean PST understands in mathematics it is important to define shapes by their properties, although they did not explicitly state ideas about properties for Descriptive or Relational level codes.

Visuals Matter (Visual Variations of shape) (mentioned only visual variations and omitted the mathematical properties, but without specifically devaluing or excluding properties, simply omitted): PST states that s/he will provide or importance of varied visuals (varied orientations and/or varied types of a shape and/or non-examples compared to examples) which are important aspects to support learning, but did not mention properties (neither mentioned the word "properties" in their responses nor provided any specific property).

Visual Problematic:

a. Evidence of PST's visual level thinking where visual appearance or prototype image (e.g. rectangles have 2 short and 2 long sides or other inaccuracies) prominent in responses as though the PST still believes this is how shapes should be determined and/or should be taught. Or

b. PST may have explicitly said that properties or descriptions are too difficult or overcomplicate shape learning for young children, implying they will only use visuals.

Unable to Code for van Hiele levels

a. Meaning of some survey response cannot be understood or

b. Response cannot be coded as one of the above categories. For example, PSTs may mention that books are inaccurate and had wrong images or will be careful to select good books but didn't talk about any aspects that could be coded as visual, descriptive, or relational levels of thinking.

\section{Recognition That Resources Are Not Always Accurate}

Extrapolated Resources Mathematics: Statements where PSTs more broadly refer to resources (not limited to books) which are inaccurate and just not specific to shapes. Or, participant mentioned to take extra caution when using resources to teach any mathematics topics or Carefully select resources before using to teach math topics since they represent misconceptions.

Shape Resources Broad: Explicit statement where PSTs' more broadly refer to resources (not limited to books) which are inaccurate or mention the example of misconception and wrong description about shapes provided through the resources or critiquing the resources by saying that select the resources with caution or be critical about the attributes of resources or confusion created by resources.

Explicit Shape-Related Books: Explicit statements point out the shape inaccuracies in books, or the feeling of disbelief, skepticism, doubt etc. regarding the content of the book. These may include statements questioning the content of book or critiquing the book or confusions caused by the book or wrong descriptions in the book or misconception in the book. 
Implicit Shape-Related Books: Implicit evidence that participant recognized books can be inaccurate about shapes. Coder suspects or believes the participant recognized the inaccuracy of books (communicated in implicit manner with words such as "be cautious about using books" "careful" "mindful" "watch out for" "carefully select" that doesn't explicitly say they know books or other resources are inaccurate, but seems to imply it).

No evidence: No such statements that indicate any discontent, or dissatisfaction regarding the content of the book. 


\section{APPENDIX D: How to Implement Shape-Book Critique Activity}

Use Revised Rubric: Traffic Light Rating Scale can be downloaded for free from (Nurnberger-Haag, 2018, Open source access https://ibrary.osu.edu/ojs/index.php/OJSM/article/view/6041)

\section{Prior to Activity:}

\section{Select Books}

- The book needs to include at least 3 shapes.

- The shapes need to be named. In other words, the book intends to teach children about mathematical shapes.

- Have PSTs or ISTs bring books if possible, or provide for them

\section{Assign Articles to Read Prior to Activity}

- Open source article written for teachers that contains the rating scale (Nurnberger-Haag, 2018)

- If possible, Cockcroft \& Marshall (1999) to illustrate the differences between 2D and 3D shapes and Roberts (2007) to focus on quadrilateral classifications

\section{Materials:}

- If possible, print rating scale in color

- If possible, have red, yellow, and green writing utensils to color code on scale

\section{Implementation:}

1) Small Groups Use Rating Scale to Evaluate a Book

- If constrained by book availability, pairs, trios, and quads seemed to learn similarly across courses

2) Monitor Small Group Discussions and Select Shares

- Select groups to share for each of the issues you want to discuss

3) Ensure Whole Class Discussion includes the following issues

- 2D vs. 3D conflation of multiple shapes (especially the most frequent shapes of circle, triangle, square, and rectangle)

- To clarify quadrilateral identification:

- Emphasize the prefix and root word of "rect-angle" as meaning right-angled to help adults reconceive of the category of rectangle in accurate ways (Nurnberger-Haag, 2018).

- Use at least one example of a book with a partitive rectangle definition that shows squares and rectangles as completely separate (e.g., one page for each with no squares on rectangle page) to discuss how this misleads children.

- Use an example of a book that accurately tries to explain a hierarchical definition (i.e., that a square is a rectangle), but still misrepresents properties of squares and rectangles and/or fails to fully represent the idea because it omits images of squares as examples of rectangles. (An example of such a book is Twizzlers Shapes and Patterns; Pallotta, 2002).

- To clarify rhombus, bring a book such as Squares, Rectangles, and Other Quadrilaterals (Adler, 2018) that inaccurately states a rhombus cannot have right angles. If possible, also discuss a PST's book that includes rhombus.

- To clarify trapezoid, ensure at least one book is discussed to help PSTs recognize that the prototypical trapezoid is really an isosceles trapezoid and discuss the true inclusive and exclusive definitions. 